Document downloaded from:

http://hdl.handle.net/10251/82717

This paper must be cited as:

Fernández Domene, RM.; Sánchez Tovar, R.; Lucas-Granados, B.; Garcia-Anton, J. (2016). Improvement in photocatalytic activity of stable WO3 nanoplatelet globular clusters arranged in a tree-like fashion: Influence of rotation velocity during anodization. Applied Catalysis B: Environmental. 189:266-282. doi:10.1016/j.apcatb.2016.02.065.

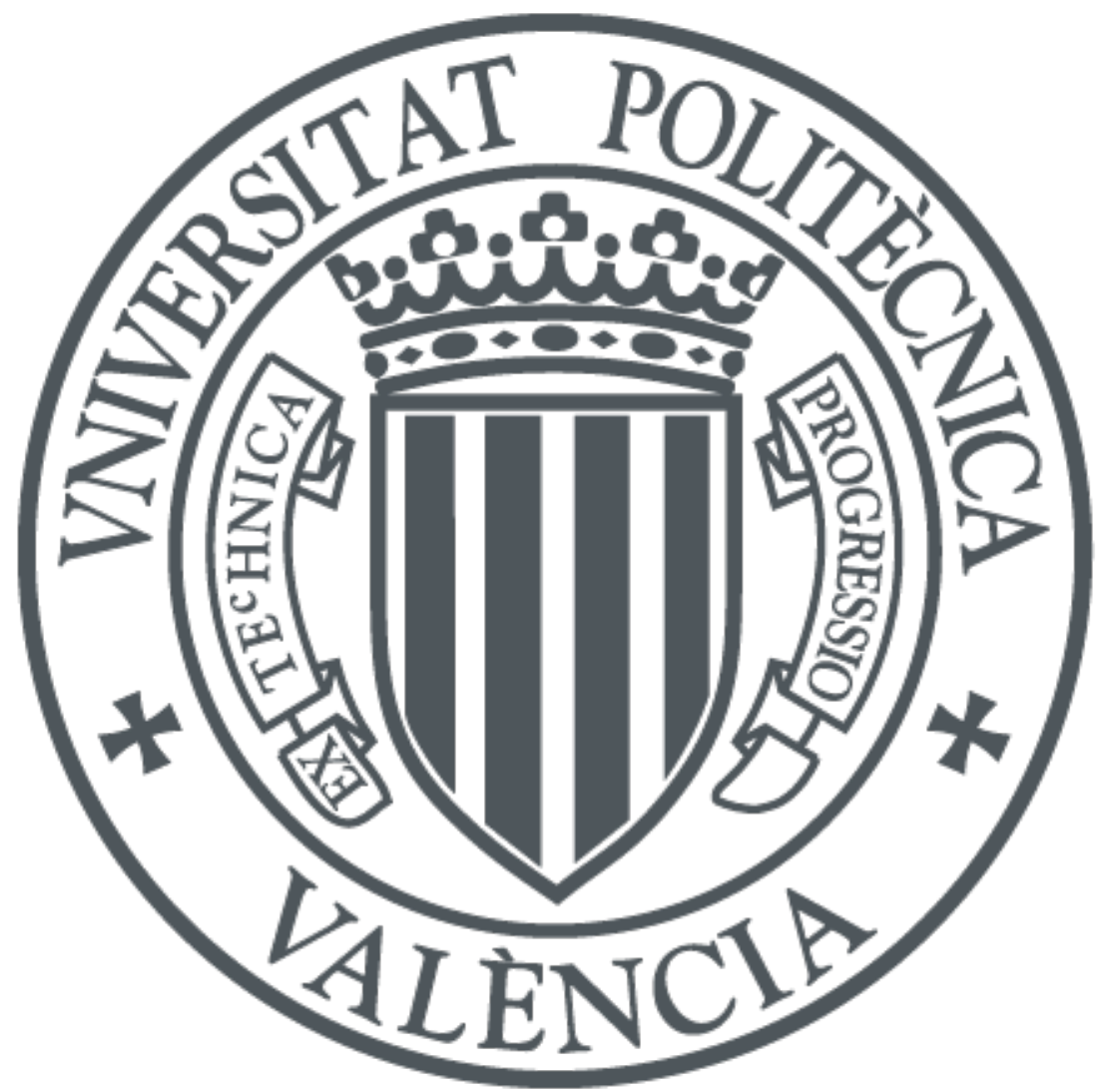

The final publication is available at

http://doi.org/10.1016/j.apcatb.2016.02.065

Copyright Elsevier

Additional Information 


\section{IMPROVEMENT IN PHOTOCATALYTIC ACTIVITY OF STABLE WO NANOPLATELET GLOBULAR CLUSTERS ARRANGED IN A TREE-LIKE FASHION: INFLUENCE OF ROTATION VELOCITY DURING ANODIZATION}

Fernández-Domene, R.M. ${ }^{\text {; }}$ Sánchez-Tovar, R. ${ }^{\text {; }}$ Lucas-Granados, B. ${ }^{\text {a }}$ García-

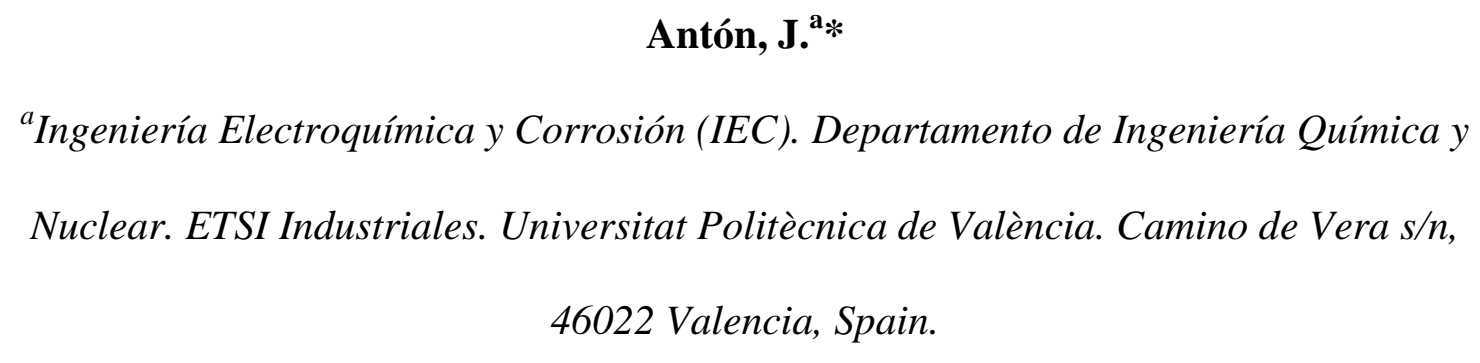
Tel. 34-96-387 76 32, Fax. 34-96-387 76 39, e-mail: jgarciaa@iqn.upv.es This study investigates the influence of controlled hydrodynamic conditions during anodization of tungsten (W) on the morphological, electrochemical and photocatalytic properties of a novel $\mathrm{WO}_{3}$ nanostructure: globular clusters of nanoplatelets associated in a tree-like fashion. For this purpose different techniques such as Field-Emission Scanning Electronic Microscopy (FE-SEM), electrochemical impedance spectroscopy (EIS) measurements, Mott-Schottky (M-S) analysis and photoelectrochemical water splitting tests have been carried out. Photoanodes obtained at $375 \mathrm{rpm}$ showed the best photoresponse, much higher than that of conventional $\mathrm{WO}_{3}$ nanoplatelets, which can be ascribed to a noteworthy increase in the electrochemically active surface area leading to improved charge transfer at the interface. Moreover, the improved $\mathrm{WO}_{3}$ nanostructure displayed very good long-term photostability when irradiated with AM 1.5 illumination, thus solving the recurrent problem of the poor stability of $\mathrm{WO}_{3}$ against photodegradation processes.

KEYWORDS: $\mathrm{WO}_{3}$ nanostructures; anodization; hydrodynamic conditions; photocatalytic activity; water splitting. 


\section{INTRODUCTION}

Semiconducting metal oxides, such as $\mathrm{TiO}_{2}[1-3], \mathrm{WO}_{3}$ [4-10], $\mathrm{Fe}_{2} \mathrm{O}_{3}[11,12]$ or $\mathrm{ZnO}$ $[13,14]$, are being widely investigated for their use as photoanodes due to the wide range of properties they can offer. Among the key functional properties that these oxides must have for photoelectrochemical processes, the resistance to degradation in the required environments (chemical dissolution, electrochemical corrosion, photocorrosion and other light-driven degradation processes) is of critical importance $[15,16]$. Therefore, when using a photoelectrode, it is essential to assure that it is resistant to degradation and that its photoelectrochemical response is stable with time.

On the other hand, tungsten trioxide $\left(\mathrm{WO}_{3}\right)$ has generated great interest in the last years due to its numerous applications in electrochromic devices, gas sensors, photoelectrochemical water splitting or photodegradation of organic compounds [6-8, 10, 17-27]. To increase the efficiency of the $\mathrm{WO}_{3}$-based photoanodes, nanostructured electrodes (such as nanotubes, nanorods/nanowires, nanoplatelets or nanoflakes) are required to provide a high specific surface area $[4-10,18-20,22-31]$. Although $\mathrm{WO}_{3}$ is resistant to chemical attack in acidic media [26, 32-34], its stability under illumination is not good in numerous electrolytes, even in strong acid solutions, which has been manifested in many works as a decay of the initial photocurrent density with time upon illumination [30, 35-38].

In a recent paper [39] we presented a novel $\mathrm{WO}_{3}$ nanostructure with very high surface

area formed by tree-like nanoplatelets clusters. This innovative nanostructure was synthesized by anodization in sulfuric acid media in the presence of fluoride anions and 
under controlled hydrodynamic conditions using a rotating disc electrode (RDE), and its photoresponse was very high compared with that of samples synthesized under stagnant conditions. Although the new nanostructure formed under hydrodynamic conditions presented larger surface areas and provided higher photocurrent densities than that formed at $0 \mathrm{rpm}$, it was also observed that at high rotation velocities (2000 rpm) the thickness of the nanoplatelet layer, and hence the surface area exposed to the electrolyte, was significantly lower than at lower rotation velocities $(500 \mathrm{rpm})$. This fact indicated that the influence of hydrodynamic conditions on the formation and growth of the new tree-like nanostructure was not linear, and further study was necessary to investigate the mechanism of formation of these $\mathrm{WO}_{3}$ nanoplatelets clusters.

The objectives of the present study are, therefore: (1) to optimize the dimensions and photoactivity of the tree-like nanoplatelets by modifying the rotation velocity of the $\mathrm{RDE}$ and (2) to find optimal conditions to assure that the new nanostructure does not undergo degradation under illumination, that is, its photoresponse remains stable with time. To accomplish both objectives, different techniques have been used, such as FieldEmission Scanning Electronic Microscopy (FE-SEM), electrochemical impedance spectroscopy (EIS), Mott-Schottky (M-S) analysis and photoelectrochemical measurements.

\section{EXPERIMENTAL PROCEDURE}

Tungsten samples were teflon-coated cylindrical bars of $8 \mathrm{~mm}$ in diameter. Before anodization, samples were abraded using 220, 500, 1000 and 4000 grit SiC papers to 
remove scratches and other imperfections from the surface. Then, the samples were sonicated in ethanol for $2 \mathrm{~min}$ and dried in a $\mathrm{N}_{2}$ stream. Anodization of tungsten samples was carried out in a $1.5 \mathrm{M} \mathrm{H}_{2} \mathrm{SO}_{4}+0.1 \mathrm{M} \mathrm{NaF}$ electrolyte, at $20 \mathrm{~V}$ and $50{ }^{\circ} \mathrm{C}$ for 4 hours, under controlled hydrodynamic conditions (from 0 to $1000 \mathrm{rpm}$ ) by using a rotating disc electrode (RDE) and a platinum mesh as cathode. The area of the working electrode (tungsten sample) exposed to the electrolyte was $0.5 \mathrm{~cm}^{2}$. After anodization, samples were annealed at $400{ }^{\circ} \mathrm{C}$ for 4 hours in the presence of oxygen. The morphology of the formed nanostructures was characterized by Field Emission Scanning Electron Microscopy (FE-SEM).

Electrochemical measurements (electrochemical impedance spectroscopy (EIS) and Mott-Schottky analysis) were performed under dark conditions in a $1 \mathrm{M} \mathrm{HCl}$ electrolyte. $\mathrm{An} \mathrm{Ag} / \mathrm{AgCl}(3 \mathrm{M} \mathrm{KCl})$ electrode was the reference electrode, and a platinum tip was the counter electrode. The illuminated area of the working electrode exposed to the electrolyte was $0.13 \mathrm{~cm}^{2}$. For EIS measurements at open circuit potential, the potential perturbation amplitude was $10 \mathrm{mV}$, in the frequency range of $10 \mathrm{kHz}$ to $10 \mathrm{mHz}$. MottSchottky plots were determined at a constant frequency of $5 \mathrm{kHz}$ using a $10 \mathrm{mV}$ amplitude signal and scanning the potential from a value of $0.5 \mathrm{~V}_{\mathrm{Ag} / \mathrm{AgCl}}$ in the negative direction at a rate of $50 \mathrm{mV} \mathrm{s}^{-1}$.

Photocurrent density-potential curves and stability tests were carried out in many different electrolytes using an Autolab PGSTAT302N potentiostat under simulated sunlight illumination AM $1.5\left(100 \mathrm{~mW} \mathrm{~cm}^{2}\right)$, with the purpose of finding an electrolyte where the $\mathrm{WO}_{3}$ samples were stable. The electrochemical cell was the same as that described above for the electrochemical measurements. Photocurrent density-potential 
curves were recorded by scanning the potential from $-0.24 \mathrm{~V}$ to $1.02 \mathrm{~V}$ with a scan rate of $2 \mathrm{mV} \mathrm{s}^{-1}$, switching the light on and off (60 s in the dark and $20 \mathrm{~s}$ in the light) to obtain in the same measurement photocurrent and dark current values. Afterwards, a potential of $1.02 \mathrm{~V}$ was kept constant for 1 hour under illumination to evaluate the samples stability. Additionally, the indirect band-gap energy of the samples was determined measuring the photocurrent density spectrum at $1.02 \mathrm{~V}_{\mathrm{Ag} / \mathrm{AgCl}}$ in the wavelength range from 300 to $500 \mathrm{~nm}$, in a $1 \mathrm{M} \mathrm{HCl}$ electrolyte.

\section{RESULTS AND DISCUSSION}

\subsection{Morphological characterization (FE-SEM)}

Figure 1 shows the FE-SEM images of the samples anodized in the $1.5 \mathrm{M} \mathrm{H}_{2} \mathrm{SO}_{4} / 0.1 \mathrm{M}$ $\mathrm{NaF}$ solution at different rotation velocities. It can be observed that in all cases, the nanostructures formed on the $\mathrm{W}$ surface presented nanoplatelet morphology, as other authors reported when anodizing in similar acid electrolytes [18, 20, 25, 29, 39, 40]. However, the dimensions and morphology of these nanoplatelets were influenced by hydrodynamic conditions. At $0 \mathrm{rpm}$ (Figure 1a), nanoplatelets grew quite orderly and almost orthogonal to the electrode surface. The nanoplatelets layer was crisscrossed by numerous cracks and at least another nanoplatelets layer could be observed underneath the first one. At $125 \mathrm{rpm}$ (Figure 1b), nanoplatelets started forming globular clusters, although most of these clusters still grew forming a single-level layer; in this case, several cracks were also observed on the $\mathrm{WO}_{3}$ layer. At rotation velocities higher than $125 \mathrm{rpm}$ (Figures 1c to 1g), nanoplatelets globular clusters grew in a tree-like manner, forming a multilevel $\mathrm{WO}_{3}$ layer resembling a coniferous forest or a coral reef seen from 
above and thus exposing more surface area to the electrolyte. It can be observed that at high rotation velocities (Figures 1e to 1 g) these nanoplatelet clusters were denser than at lower rpm, although their size did not vary appreciably with the rotation velocity. Figure 2a plots the total thickness of the nanoplatelets layer and the \% of surface covered by these nanostructures as a function of the rotation velocity. The total thickness was obtained from FE-SEM cross-sectional images. Figure $\mathbf{2 b}$ shows, as an example, the FE-SEM cross-sectional images of the samples anodized under 0 and 500 rpm. It can be seen that the thickness of the $\mathrm{WO}_{3}$ nanoplatelets layer increased with increasing rpm until reaching a maximum value at $375 \mathrm{rpm}$, and then decreased again. Concerning the $\%$ of surface coverage, it decreased more or less linearly with rotation velocity. These differences in dimensions and surface coverage will be discussed in the next section when studying the current density transients recorded during the anodization process.

\subsection{Influence of rotation velocity on the anodization process}

In order to understand the influence of rotation velocity on the formation and growth of $\mathrm{WO}_{3}$ nanoplatelets, current density transients recorded during the anodization of the $\mathrm{W}$ samples are presented in Figure 3. A notable decrease in current density can be observed during the first seconds of anodization, regardless of the rotation velocity. This decrease is associated with the formation of a compact $\mathrm{WO}_{3}$ layer on the electrode surface $[4,39,41]$, according to:

$$
\mathrm{W}+3 \mathrm{H}_{2} \mathrm{O} \rightarrow \mathrm{WO}_{3}+6 \mathrm{H}^{+}+6 \mathrm{e}^{-}
$$


Subsequently, current density started increasing, indicating the dissolution of the $\mathrm{WO}_{3}$ layer due to the effect of $\mathrm{H}^{+}[24,29,39,42]$ and $\mathrm{F}^{-}[24,39,41]$. This dissolution process resulted in the release of soluble species from the electrode surface:

$$
\begin{gathered}
\mathrm{WO}_{3}+2 \mathrm{H}^{+} \rightarrow \mathrm{WO}_{2}^{2+}+2 \mathrm{H}_{2} \mathrm{O} \\
\mathrm{WO}_{3}+6 \mathrm{H}^{+}+\mathrm{nF}^{-} \rightarrow\left[\mathrm{WF}_{\mathrm{n}}\right]^{(\mathrm{n}-6)}+3 \mathrm{H}_{2} \mathrm{O}
\end{gathered}
$$

Afterwards, current density gradually decreased again, eventually reaching a steadystate value. This decrease and the later stabilization of current density can be explained by the precipitation of soluble species upon reaching supersaturation conditions near the electrode surface. This precipitation in the form of nanoplatelets took place according to the following reactions $[24,29,39,42]$ :

$$
\begin{aligned}
& \mathrm{WO}_{2}^{2+}+2 \mathrm{H}_{2} \mathrm{O} \rightarrow \mathrm{WO}_{3} \cdot \mathrm{H}_{2} \mathrm{O}+2 \mathrm{H}^{+} \\
& \mathrm{WO}_{2}^{2+}+3 \mathrm{H}_{2} \mathrm{O} \rightarrow \mathrm{WO}_{3} \cdot 2 \mathrm{H}_{2} \mathrm{O}+2 \mathrm{H}^{+}
\end{aligned}
$$

In a previous work is was demonstrated through Raman spectroscopy that the main constituent of the hydrated $\mathrm{WO}_{3}$ nanoplatelets was $\mathrm{WO}_{3} \cdot 2 \mathrm{H}_{2} \mathrm{O}$, although the presence of some $\mathrm{WO}_{3} \cdot \mathrm{H}_{2} \mathrm{O}$ was also detected [39]. After annealing the samples at $400{ }^{\circ} \mathrm{C}$ for 4 hours, crystalline monoclinic $\mathrm{WO}_{3}$ was obtained [39].

Under static conditions ( $0 \mathrm{rpm})$, current densities recorded during the whole anodization process were notably lower than under hydrodynamic conditions. Moreover, steadystate values were attained much earlier than with rotation, indicating that the $\mathrm{WO}_{3}$ 
nanoplatelet layer completely covered the electrode surface after $2000 \mathrm{~s}$ from the beginning of the anodization process.

As the rotation velocity increased, current density values associated with the dissolution of the initial $\mathrm{WO}_{3}$ layer also increased. This fact is explained by taking into account the velocity profile of the electrolyte near the RDE. When the RDE rotates, the solution is drawn up from the bulk electrolyte towards the electrode along the axis normal to the surface, and afterwards, due to the centrifugal force, it is expelled towards the outer edge of the electrode. The expression for the fluid velocity in the normal direction, $v_{y}$, is [43]:

$$
v_{y}=-0.51 \omega^{3 / 2} v^{-1 / 2} y^{2}
$$

where $\omega$ is the angular velocity, $v$ the kinematic viscosity of the fluid, and $y$ (in cylindrical coordinates) the distance from the electrode surface in the normal direction.

Eq. (6) implies that $v_{y}$ increases (in absolute value) with increasing the rotation velocity $(\omega)$. Hence, faster electrode rotation permitted the ions in the electrolyte $\left(\mathrm{F}^{-}\right.$and $\left.\mathrm{H}^{+}\right)$to transport to the electrode more rapidly (both by convection and by diffusion through the stagnant layer), resulting in higher current densities being measured at the working electrode due to the enhancement of the $\mathrm{WO}_{3}$ dissolution (eqs. (2) and (3)), and the subsequent exposure of the $\mathrm{W}$ bare surface to the electrolyte, which oxidized again (eq. (1)). Consequently, an increase in the rotation velocity increased the release of soluble species from the electrode surface, which would result in a higher precipitation rate of hydrated $\mathrm{WO}_{3}$ in the form of nanoplatelets (eqs. (4) y (5)) due to supersaturation conditions being reached earlier than at low $\omega$. However, it was observed before from 
the FE-SEM images that the thickness of the $\mathrm{WO}_{3}$ nanoplatelets layer, as well as the degree of surface covered by them, were smaller at high rotation velocities (Figure 2). This is explained by the existence of a radial flow because of the centrifugal force that threw the electrolyte outwards from the center of the electrode, with the fluid velocity increasing towards the edge of the disc with increasing distance from the rotation axis in the radial direction $(r)$ and $\omega$, according to [43]:

$$
v_{r}=0.51 \omega^{3 / 2} v^{-1 / 2} r y
$$

Consequently, soluble species near the electrode surface were constantly swept away radially at a velocity directly dependent on the rotation velocity and the radius. As described above, for nanoplatelets to precipitate on the electrode surface, soluble species must reach a supersaturation concentration near the electrode. As $\omega$ increased, this critical concentration was more difficult to accomplish, especially at high values of $r$.

Therefore, hydrodynamic conditions influenced the growth of nanoplalets in two opposite ways: on the one hand, hydrodynamic conditions enhanced mass transfer towards the electrode surface, thus favoring the formation of soluble species responsible for the formation of nanoplatelets; on the other hand, mechanical convection reduced the concentration of soluble species close to the electrode surface, hence decreasing the nanoplatelets growth rate by precipitation $[5,29,39]$. In this case, according to the FESEM images and the nanoplatelet layer thicknesses shown in Figure 2, the first factor (enhancement of mass transfer, soluble species formation and subsequent precipitation) had more influence at low rotation velocities (up to $375 \mathrm{rpm}$ ), while at rotation velocities higher than $375 \mathrm{rpm}$ it was the second factor (decrease of soluble species 
concentration near the surface) that predominated over the first one in determining the formation and growth of nanoplatelets, since the thickness of the nanoplatelets layer decreased at high rpm.

Current densities recorded at the end of the 4-hours anodization process also increased with increasing rotation velocity. These values represent an approximately steady-state between the dissolution of the $\mathrm{WO}_{3}$ layer (eq. (1)) and the precipitation of soluble species to hydrated $\mathrm{WO}_{3}$ in the form of nanoplatelets (eqs. (4) and (5)). Hence, an increase in steady-state current density with $\omega$ implies that the degree of surface coverage was smaller at high $\omega$, which is also consistent with the previous results (Figure 2).

\subsection{Electrochemical characterization}

The electrochemical characterization of the $\mathrm{WO}_{3}$ nanostructures/electrolyte interface was performed in the dark through EIS measurements and Mott-Schottky analysis.

Figure 4 shows the Nyquist and Bode-phase diagrams for all the samples, anodized at different rotation velocities. Nyquist plots (Figure 4a) exhibit one or two unfinished semicircles, depending on the rotation velocity, and relatively low impedance values. At 0 and $125 \mathrm{rpm}$, two semicircles can be discerned, one at intermediate frequencies and the other at low frequencies (inset in Figure 4a), which correspond with the two peaks that appear in the Bode-phase plots (Figure 4b). At $500 \mathrm{rpm}$ and higher rotation velocities (750 and $1000 \mathrm{rpm}$ ), only one semicircle can be discerned from Nyquist plots, in accordance with the peak observed in the phase angle. At 250 and $375 \mathrm{rpm}$, a single 
semicircle is appreciable in Nyquist plots, but two time constants can be detected from the Bode-phase plots. The first semicircle observed in the Nyquist plots at 0 and 125 rpm has a considerably lower amplitude than the second semicircle, being the amplitude of the latter more similar to that of the single semicircle observed at higher rotation velocities. Therefore, this first time constant can be associated with some surface effects related to the specific morphology of the samples anodized at low rotation velocities, especially at 0 and $125 \mathrm{rpm}$. At $0 \mathrm{rpm}$, the morphology of the $\mathrm{WO}_{3}$ nanostructures was observed to be vertically-alligned nanoplatelets, while at $125 \mathrm{rpm}$ this morphology slightly changed and single nanoplatelets started forming globular clusters, but in both cases nanoplatelets formed a single-level layer (Figure 1). As rotation velocity increased, globular clusters of nanoplatelets began forming multilevel layers, and this first time constant was not so clearly observed from EIS plots (at 250 and $375 \mathrm{rpm}$, where a transition ocurred) or simply disappeared (500, 750 and $1000 \mathrm{rpm})$. The second time constant, which is common for all the samples, can consequently be associated with the charge-transfer resistance and the double layer capacitance of the $\mathrm{WO}_{3}$ nanostructures.

Since the impedance response of the samples, especially the variation of the phase angle with frequency, was observed to change depending on the rotation velocity used during anodization, EIS experimental data have been fitted to the electrical equivalent circuits shown in Figure 5a (from 0 to $375 \mathrm{rpm}$ ) and in Figure 5b (from 500 to $1000 \mathrm{rpm}$ ). In these circuits, $R_{S}$ is the electrolyte resistance; the $R_{1}-C P E_{1}$ time constant is associated with some surface effects due to the morphology of the nanoplatelet layer formed at 0 and low rpm values (mainly $125 \mathrm{rpm}$ ), while the $R_{\text {nano }}-C P E_{\text {nano }}$ time constant is related to the charge transfer between the $\mathrm{WO}_{3}$ nanostructure and the electrolyte. Constant 
Phase Elements (CPEs) have been used instead of pure capacitors, to account for the non-ideality of the system under measurement. The impedance of a constant-phase element is defined as:

$$
Q=Z_{C P E}=\left[C(j \omega)^{n}\right]^{-1}
$$

where $n$, defined as a CPE power, is an adjustable parameter that lies between -1 and 1 . For $n=1$ the CPE describes an ideal capacitor, and for $n=0$ the CPE is an ideal resistor. For $0.5<n<1$ the CPE describes a frequency dispersion of time constants due to local heterogeneities in the dielectric material. A pure inductance yields $n=-1$.

CPEs of the $\mathrm{WO}_{3}$ nanostructures have been converted into pure capacitances, $C$, by using the following equation $[44,45]$ :

$$
C_{\text {nano }}=\frac{\left(Q_{\text {nano }} \cdot R\right)^{1 / \alpha}}{R}
$$

where $Q_{\text {nano }}$ is the impedance of the $C P E_{\text {nano }}$. For the equivalent circuit shown in Figure 5a, $R=R_{\text {nano }}$, while for the equivalent circuit in Figure 5b, $R=\left(\frac{R_{S} \cdot R_{\text {nano }}}{R_{S}+R_{\text {nano }}}\right)[44,45]$.

The values of $R_{\text {nano }}$ and $C_{\text {nano }}$ have been plotted against the rotation velocity in Figure 6. A clear correlation between both values is evident: high $R_{\text {nano }}$ values imply low $C_{\text {nano }}$ values, and vice versa. At 0 and $125 \mathrm{rpm}$, both parameters were similar, but as rotation velocity increased (up to $500 \mathrm{rpm}$ ), $R_{\text {nano }}$ decreased and $C_{\text {nano }}$ increased. This fact can be 
explained by an increase in the surface area exposed to the electrolyte, which increased the double layer capacitance and reduced the charge-transfer resistance at the nanostructure/electrolyte interface [41] due to a large number of electrochemically active sites being permeated by the electrolyte [8]. At higher rotation velocities, $R_{\text {nano }}$ increased again whereas $C_{\text {nano }}$ decreased. Although the morphology of the $\mathrm{WO}_{3}$ nanostructures formed at 750 and $1000 \mathrm{rpm}$ was similar than that obtained at lower rpm (Figure 1), nanoplatelets clusters formed at high rotation velocities were observed to grow in a more compact manner and, besides, the thickness of the $\mathrm{WO}_{3}$ nanoplatelet layer was lower for these samples (Figure 2), which resulted in a decrease of the active surface area exposed to the electrolyte. These factors led to a reduction in the efficiency of electron transport [30] and, therefore, the charge-transfer resistance increased and the double layer capacitance decreased at 750 and $1000 \mathrm{rpm}$.

In order to investigate the semiconducting properties of the $\mathrm{WO}_{3}$ nanoplatelets layer, the electrochemical interfacial capacitance was measured as a function of the applied potential. Mott-Schottky (M-S) analysis was performed to obtain the donor density, $N_{D}$, and the flat-band potential, $U_{F B}$, of the nanostructures formed at different rotation velocities. Figure 7 shows the Mott-Schottky plots of the different samples. The positive slopes of these M-S plots are characteristic of $n$-type semiconductors, and the nanostructure/electrolyte interface can be described by the corresponding Mott-Schottky equation:

$$
\frac{1}{C^{2}}=\frac{1}{C_{H}^{2}}+\frac{2}{\varepsilon_{r} \varepsilon_{0} e N_{D}}\left(U-U_{F B}-\frac{k T}{e}\right)
$$


where $C$ is the measured interfacial capacitance, $C_{H}$ is the capacitance of the Helmholtz layer, $\varepsilon_{r}$ is the relative permittivity or dielectric constant of the $\mathrm{WO}_{3}$ nanostructures (a value of 50 has been assumed for the $\left.\mathrm{WO}_{3}[9,22,35,36]\right), \varepsilon_{0}$ is the vacuum permittivity $\left(8.85 \cdot 10^{-14} \mathrm{~F} / \mathrm{cm}\right), e$ is the electron charge $\left(1.60 \cdot 10^{-19} \mathrm{C}\right), U$ is the applied potential, $k$ is the Boltzmann constant $\left(1.38 \cdot 10^{-23} \mathrm{~J} / \mathrm{K}\right)$ and $T$ is the absolute temperature.

Values of $N_{D}$ and $U_{F B}$ can be determined from the slope and the intercept, respectively, of a linear representation between $C^{-2}$ and $U$, according to eq. (10). It is noteworthy that $C_{H}$ does not influence the value of $N_{D}$, but it affects the value of $U_{F B}$. It is usually assumed that the Helmholtz layer capacitance is so large compared with the space charge layer capacitance that the total capacitance measured can be treated as the space charge layer capacitance and the potential drop caused by the applied potential occurs entirely within the space charge region. However, in highly doped semiconductors (such as nanostructured metal oxides), $C_{H}$ should not be neglected, since a significant part of the potential difference at the semiconductor/electrolyte interface extends to the Helmholtz layer in the solution [46-48]. Therefore, in the present study, $C_{H}$ values have not been neglected. For practical purposes, since the electrolyte used in electrochemical measurements $(1 \mathrm{M} \mathrm{HCl})$ was sufficiently concentrated, the capacitance response of the Guoy-Chapman diffuse layer can be ignored, so $C_{H} \approx C_{\text {nano }}$.

Table 1 shows the values of $N_{D}$ and $U_{F B}$ for the $\mathrm{WO}_{3}$ nanostructures synthesized at different rotation velocities. As mentioned above, $U_{F B}$ values have been determined by taking into account the capacitance of the Helmholt layer in eq. (10). It can be seen that $N_{D}$ were very high, of the same order of magnitude than values reported in the literature for $\mathrm{WO}_{3}$ nanoplatelets, nanoparticles and nanorods [9, 22, 35, 36, 49]. Samples 
anodized at 250, 375 and $500 \mathrm{rpm}$ presented significantly higher donor densities than the rest of the samples, which can be explained by an increase of the interfacial capacitance due to the larger surface area exposed to the electrolyte for the samples anodized at intermediate rotation velocities, resulting in higher concentration of oxygen vacancies. These results are consistent with the increase in $C_{n a n o}$ and the decrease in $R_{\text {nano }}$ (increase in the nanostructures conductivity) observed above for these samples (Figure 6). Concerning the $U_{F B}$, there was no clear tendency with rotation velocity, and values varied within a small range from 0.23 to $0.30 \mathrm{~V}_{\mathrm{Ag} / \mathrm{AgCl}}$, similar to values obtained by other authors $[22,35,36]$.

\subsection{Degradation resistance of the samples}

As it has been mentioned in the introduction section, resistance to degradation in a given environment under illumination is a critical requirement for the photoanode material. The first step is to ensure that the semiconductor oxide used as photoanode does not undergo chemical and electrochemical degradation in the dark. In general, it is not recommended to work with $\mathrm{WO}_{3}$ at $\mathrm{pH}$ higher than 4-5, since it is thermodynamically unstable and dissolves [33, 34]. Figure 8a shows the photocurrent density-potential $\left(i_{p h}-U\right)$ curves for the sample anodized at $500 \mathrm{rpm}$, recorded in different electrolytes with different $\mathrm{pH}$ values. The sample synthesized at $500 \mathrm{rpm}$ has been used throughout this section by way of illustration, and the conclusions obtained here can be perfectly extrapolated to the rest of the samples. It can be observed that the shape of the photocurrent density response of samples tested in $0.1 \mathrm{M} \mathrm{Na}_{2} \mathrm{SO}_{4}$ and $0.1 \mathrm{M}$ $\mathrm{H}_{2} \mathrm{SO}_{4}$ solutions was similar, although in the latter case, photocurrent density values were higher at potentials $U>0.8 \mathrm{~V}$, while dark current densities were similar at these 
potentials. In both cases, dark current densities were stable and very low (of the order of few $\mu \mathrm{A} \mathrm{cm}{ }^{-2}$ or even lower). These results denote that $\mathrm{WO}_{3}$ nanostructures were resistant to chemical and electrochemical degradation under dark conditions in the $0.1 \mathrm{M}$ $\mathrm{Na}_{2} \mathrm{SO}_{4}$ and $0.1 \mathrm{M} \mathrm{H}_{2} \mathrm{SO}_{4}$ electrolytes, especially in the acidic one.

On the other hand, the photocurrent density-potential curve recorded in $0.1 \mathrm{M} \mathrm{KOH}$ is completely different. Although the curve was also obtained under chopped illumination, it was difficult to distinguish between photocurrent and dark current densities (Figure 8a). The appearance of a wide peak centered at $\sim 0.5 \mathrm{~V}$ indicates that some kind of transformation in the characteristics or composition of the $\mathrm{WO}_{3}$ surface film took place. Moreover, after the photoelectrochemical test, the $\mathrm{WO}_{3}$ nanostructure was completely dissolved from the surface in contact with the $\mathrm{KOH}$ electrolyte. These results imply that $\mathrm{WO}_{3}$ nanoplatelets were unstable in alkaline media, as expected, due to the $\mathrm{OH}^{-}$induced chemical dissolution, in accordance with [32, 34, 49]:

$$
\mathrm{WO}_{3}(\mathrm{~s})+\mathrm{OH}^{-} \rightarrow \mathrm{WO}_{4}^{2-}(\mathrm{aq})+\mathrm{H}^{+}
$$

According to Anik and Cansizoglu [32], the chemical dissolution of the oxide film given in eq. (11) is the rate-determining step in the oxidation of $\mathrm{W}$ to $\mathrm{WO}_{3}$. This fact can explain the very high current densities obtained in the $0.1 \mathrm{M} \mathrm{KOH}$ electrolyte, which correspond to the active oxidation of the W substrate.

Concerning the photostability of the $\mathrm{WO}_{3}$ nanostructures synthesized at $500 \mathrm{rpm}$, Figure 8b shows the photocurrent density transients obtained at an applied potential of $1.02 \mathrm{~V}$ in the $0.1 \mathrm{M} \mathrm{Na} \mathrm{SO}_{4}$ and $0.1 \mathrm{M} \mathrm{H}_{2} \mathrm{SO}_{4}$ electrolytes. It can be observed that 
photocurrent density values considerably decreased after 1 hour of exposition to simulated sunlight, regardless of the electrolyte: a decrease of $83.9 \%$ (from 0.56 to 0.09 $\mathrm{mA} \mathrm{cm}{ }^{-2}$ ) was observed in the case of the $0.1 \mathrm{M} \mathrm{Na}_{2} \mathrm{SO}_{4}$ solution, and a decrease of $81.1 \%$ (from 1.11 to $0.21 \mathrm{~mA} \mathrm{~cm}^{-2}$ ) the $0.1 \mathrm{M} \mathrm{H}_{2} \mathrm{SO}_{4}$ electrolyte. Other authors observed a similar drop in photocurrent densities with time working with $\mathrm{WO}_{3}$ photoanodes in acidic or neutral electrolytes [30, 35-38, 49, 50].

Although it has been demonstrated that $\mathrm{WO}_{3}$ nanoplatelets were chemical and electrochemically stable in the acidic and neuter solutions, the fast decrease in photocurrent densities with time in these electrolytes indicates that samples underwent degradation under illumination. Photocorrosion is a phenomenon that takes place when the photogenerated holes in the valence band oxidize the semiconductor itself, instead of species present in the electrolyte $[16,51]$. In the case of $\mathrm{WO}_{3}$, photocorrosion reaction proceeds through the following reaction:

$$
2 \mathrm{WO}_{3}+12 \mathrm{~h}^{+} \rightleftarrows 2 \mathrm{~W}_{(\mathrm{aq})}^{6+}+3 \mathrm{O}_{2}
$$

Moreover, if holes accumulate near the semiconductor surface instead of reacting with species in the electrolyte, photocurrent density can also decrease with time due to the recombination of part of the photogenerated charge carriers (electrons and holes) [52]. A solution for these two issues (photocorrosion and recombination) can be the addition of a hole scavenger (electron donor) to the electrolyte, such as methanol $[8,9,53]$. The hole scavenger reacts with the holes at the semiconductor/electrolyte interface, thus reducing the complications arising from hole accumulation. Figure 9a shows the photocurrent density-potential curve for the sample anodized at $500 \mathrm{rpm}$, recorded in a 
$0.1 \mathrm{M} \mathrm{H}_{2} \mathrm{SO}_{4}$ electrolyte in the absence and presence of $1 \mathrm{M}$ methanol. An increase in photocurrent density values can be clearly observed in the $0.1 \mathrm{M} \mathrm{H}_{2} \mathrm{SO}_{4}+1 \mathrm{M} \mathrm{CH} \mathrm{CH}_{3} \mathrm{OH}$ solution, which indicates hole scavenging by $\mathrm{CH}_{3} \mathrm{OH}[8,9,53]$, according to the following reaction $[53,54]$ :

$$
\mathrm{CH}_{3} \mathrm{OH}(\mathrm{ads})+\mathrm{h}^{+} \rightarrow \cdot \mathrm{CH}_{2} \mathrm{OH}(\mathrm{ads})+\mathrm{H}^{+}
$$

Besides, the adsorbed intermediate radical $\cdot \mathrm{CH}_{2} \mathrm{OH}(\mathrm{ads})$, generated during the oxidation of methanol, can also effectively inject an additional electron into the conduction band of $\mathrm{WO}_{3}$ :

$$
\cdot \mathrm{CH}_{2} \mathrm{OH}(\mathrm{ads}) \rightarrow \mathrm{CH}_{2} \mathrm{O}(\mathrm{ads})+\mathrm{H}^{+}+\mathrm{e}_{\mathrm{cb}}^{-}
$$

which explains the important increase observed in photocurrent density in the presence of $\mathrm{CH}_{3} \mathrm{OH}[8,9,53]$. However, these high photocurrent density values recorded in the presence of $\mathrm{CH}_{3} \mathrm{OH}$ tended to gradually decrease with increasing irradiation time, as in the case of the electrolyte without methanol (Figure 9b). In this case, the photocurrent density decrease was of $54.6 \%$ (from 1.74 to $0.79 \mathrm{~mA} \mathrm{~cm}^{-2}$ ) in one hour. Although this photocurrent density drop is lower than that recorded in the $0.1 \mathrm{M} \mathrm{H}_{2} \mathrm{SO}_{4}$ solution, this result demonstrates that neither photocorrosion due to hole accumulation at the interface nor recombination of photogenerated electron-hole pairs were the main cause of the fast photocurrent density decrease with time under simulated sunlight.

The rapid deactivation of the $\mathrm{WO}_{3}$ electrodes upon illumination must be ascribed to a different light-driven degradation mechanism. Several authors have reported the 
occurrence of photocorrosion of $\mathrm{WO}_{3}$ induced by the formation of $\mathrm{H}_{2} \mathrm{O}_{2}$ during incomplete water oxidation (a reaction that is kinetically favored over oxygen evolution reaction (OER) in $\mathrm{WO}_{3}$ photoanodes under illumination, in spite of being thermodynamically less feasible [34, 37, 55-58]):

$$
\begin{array}{r}
2 \mathrm{H}_{2} \mathrm{O} \rightarrow 4 \mathrm{H}^{+}+\mathrm{O}_{2}+4 \mathrm{e}^{-} \quad E^{0}=1.228 \mathrm{~V}_{\mathrm{NHE}} \\
2 \mathrm{H}_{2} \mathrm{O} \rightarrow 2 \mathrm{H}^{+}+\mathrm{H}_{2} \mathrm{O}_{2}+2 \mathrm{e}^{-} \quad E^{0}=1.776 \mathrm{~V}_{\mathrm{NHE}}
\end{array}
$$

Subsequently, hydrogen peroxide interacts with the $\mathrm{WO}_{3}$ nanostructure, and peroxospecies accumulates on the surface, partially blocking it and thus reducing photoactivity $[26,37,38,53]$. These tungsten peroxide species can also induce the recombination of photogenerated electron-hole pairs at the surface of the $\mathrm{WO}_{3}$ nanostructures [38]. Hydroxyl radicals may form during the process, as well [57]:

$$
\mathrm{H}_{2} \mathrm{O} \rightarrow \cdot \mathrm{OH}+\mathrm{H}^{+}+\mathrm{e}^{-} \quad E^{0}=2.85 \mathrm{~V}_{\mathrm{NHE}}
$$

which can subsequently interact with the $\mathrm{WO}_{3}$ surface $[36,57]$, leading to the same negative consequences for the photoanode stability.

On the other hand, the oxidation of some acid counteranions $\left(\mathrm{Cl}^{-}, \mathrm{SO}_{4}{ }^{2-}, \mathrm{CH}_{3} \mathrm{SO}_{3}{ }^{-}\right.$, etc. $)$ can also take place on the photoanode surface under illumination, since holes in the valence band of $\mathrm{WO}_{3}$ have a potential of $\sim 2.97 \mathrm{~V}_{\mathrm{HNE}}$ at $\mathrm{pH} 0[56,57,59]$, enough to drive these oxidation reactions $\left(E^{0}\left(\mathrm{Cl}_{2} / \mathrm{Cl}^{-}\right)=1.358 \mathrm{~V}_{\mathrm{NHE}} ; E^{0}\left(\mathrm{~S}_{2} \mathrm{O}_{8}{ }^{2-} / \mathrm{SO}_{4}{ }^{2-}\right)=2.010 \mathrm{~V}_{\mathrm{NHE}}\right.$ $\left.E^{0}\left(\left(\mathrm{CH}_{3} \mathrm{SO}_{3}\right)_{2} / \mathrm{CH}_{3} \mathrm{SO}_{3}{ }^{-}\right)=2.12 \mathrm{~V}_{\mathrm{NHE}}[60]\right)$. Hence, the oxidation of acid counteranions can kinetically compete with peroxide formation and OER $[34,56,57,60]$. 
Hill and Choi [56] observed that the oxidation of chloride anions was the dominant photooxidation reaction taking place on the $\mathrm{WO}_{3}$ surface when immersing the photoanode in a $0.1 \mathrm{M} \mathrm{NaCl}$ solution $(\mathrm{pH}$ 1-5) under illumination. They also observed that photocurrent density values did not significantly decrease over time, which they ascribed to the effective suppression of peroxide formation by chloride oxidation. On the other hand, Augustynski and co-workers recently reported a very good photoelectrochemical behavior of nanostructured $\mathrm{WO}_{3}$ photoanodes in a methanesulfonic acid $\left(\mathrm{CH}_{3} \mathrm{SO}_{3} \mathrm{H}\right)$ electrolyte [38], achieving large and stable photocurrent densities. They ascribed this good behavior to the minimization of the $\mathrm{e}^{-}-$ $\mathrm{h}^{+}$recombination coming from the formation of a surface layer of tungsten peroxospecies, although the mechanism by which this was achieved in $\mathrm{CH}_{3} \mathrm{SO}_{3} \mathrm{H}$ solutions in particular was not clearly explained.

In order to investigate a way of suppressing or, at least, lessening the negative effects of the photo-induced generation of hydrogen peroxide on the stability of the $\mathrm{WO}_{3}$ photoanodes, $i_{p h^{-}} U$ curves and stability tests were also performed in $\mathrm{HCl}, \mathrm{NaCl}(\mathrm{pH}$ adjusted to 0 by adding small amounts of highly concentrated $(37 \%) \mathrm{HCl}$ ) and $\mathrm{CH}_{3} \mathrm{SO}_{3} \mathrm{H}$ electrolytes (Figure 10). In the case of the sample immersed in the methanesulfonic acid solution, it can be observed that recorded photocurrent densities were lower than those obtained in the electrolytes with $\mathrm{Cl}^{-}$, regardless of the chloride concentration and the applied potential (Figure 10a). Moreover, it is evident from Figure 10b that $\mathrm{WO}_{3}$ nanostructures were not stable in that solution under illumination (the photocurrent density decreased a $73 \%$ after $1 \mathrm{~h}$, a value similar to those reported above for $0.1 \mathrm{M} \mathrm{Na}_{2} \mathrm{SO}_{4}$ and $0.1 \mathrm{M} \mathrm{H}_{2} \mathrm{SO}_{4}$ electrolytes). 
On the other hand, for the $\mathrm{Cl}^{-}$containing electrolytes, it can be observed that photocurrent densities slightly decreased at $1.02 \mathrm{~V}$ as the chloride concentration increased (Figure 10a). This fact can be related to some interaction between the $\mathrm{WO}_{3}$ nanostructure and the $\mathrm{Cl}^{-}$anions, which led to a (minor) reduction in photoactivity. Regarding the stability of the photoanodes, $\mathrm{WO}_{3}$ samples were more stable in concentrated chloride solutions (i.e $5 \mathrm{M} \mathrm{NaCl}$ ) than in diluted ones (Figure 10b), since the decrease experimented by photocurrent density in the $5 \mathrm{M} \mathrm{NaCl}$ solution was the lowest (39\%) (Figure 10c). This fact can be explained by taking into account two factors. As it has been explained above, $\mathrm{Cl}^{-}$anions competed with $\mathrm{H}_{2} \mathrm{O}$ for the valence band holes; thus, the oxidation of $\mathrm{Cl}^{-}$to $\mathrm{Cl}_{2}$ somewhat limited the incomplete water oxidation to hydrogen peroxide and hence moderately improved the photostability of the samples [56]. However, little differences can be discerned in the photocurrent density response of the samples immersed in the $1 \mathrm{M} \mathrm{HCl}$ and $3 \mathrm{M} \mathrm{NaCl}(\mathrm{pH} 0)$, but this response was different in the $5 \mathrm{M} \mathrm{NaCl}(\mathrm{pH} 0)$ electrolyte, where the decrease in photocurrent density with time was not abrupt (Figure 10b). Therefore, the presence of $\mathrm{Cl}^{-}$anions competing with water for the valence band holes was not the only factor that positively influenced the photoanode stability. The other factor was the reduction in the activity of water $\left(a_{W}\right)$. In diluted or moderately concentrated electrolytes, $a_{W}$ usually takes values very close to one; in highly concentrated solutions, however, $a_{W}$ falls below unity, since hydration of ions removes water from the "role" of solvent to become a part of the hydrated ion, thus reducing its thermodynamic activity. Hence, a reduction in $a_{W}$ with increasing electrolyte concentration can be understood as a reduction in the amount of free $\mathrm{H}_{2} \mathrm{O}$ molecules in the solution. Since water was the reacting species in the 
formation of hydrogen peroxide and hydroxyl radicals, according to eq. (16) and eq. (17), a reduction in $a_{W}$ led to a reduction in the formation of $\mathrm{H}_{2} \mathrm{O}_{2}$ and $\bullet \mathrm{OH}$.

From osmotic coefficient values $(\phi)$ of $\mathrm{NaCl}$ solutions [61, 62], $a_{W}$ has been calculated according to the next equation $[63,64]$ :

$$
\ln \left(a_{W}\right)=-\phi M_{W} \varsigma m
$$

where $M_{W}$ is the molar mass of water and $\varsigma$ is the stoichiometric parameter, i.e., the number of ion moles produced by complete dissociation of one mole of salt (for a 1:1 salt such as $\mathrm{NaCl}$ or $\mathrm{LiCl}, \varsigma$ equals 2); notice that molality $m$ is expressed in kilomole of solute per kilogram of solvent (or mole of solute per gram of solvent) so the units in eq. (18) are consistent. In the present case, $a_{W}$ for the $3 \mathrm{M} \mathrm{NaCl}$ electrolyte is 0.88 , while $a_{W}$ for the $5 \mathrm{M} \mathrm{NaCl}$ electrolyte is 0.78 . Consequently, this decrease in $a_{W}$ contributed to stabilize to some extent the photoanode immersed in the latter electrolyte by reducing the formation of hydrogen peroxide and hydroxyl radicals through eq. (16) and eq. (17).

Since a decrease in $a_{W}$ has been observed to positively affect the photoresponse of the $\mathrm{WO}_{3}$ nanostructures in terms of an improvement of their photodegradation resistance, additional photoelectrochemical tests were carried out in highly concentrated chloride solutions. In $\mathrm{NaCl}$ electrolytes, $a_{W}$ cannot be decreased below a value of $\sim 0.75$ [61], so $\mathrm{LiCl}$ solutions were used instead for that purpose. Given that the $\mathrm{Li}^{+}$cation is smaller than the $\mathrm{Na}^{+}$one but both have the same charge, the smallest cation produces the strongest electrical field, resulting in stronger interactions with the surrounding water molecules. Thus, working with $\mathrm{LiCl}$ solutions, $a_{W}$ can be further reduced [65]. In 
Figure 11, the variation of $a_{W}$ with molar concentration for $\mathrm{LiCl}$ electrolytes is plotted. It can be observed that $a_{W}$ continuously decreases as $\mathrm{LiCl}$ concentration increases, this effect being more marked at high concentrations, where $a_{W}$ values are very low, close to zero. In this figure, activity of $\mathrm{Cl}^{-}$anions is also represented against the molar concentration of $\mathrm{LiCl}$. This activity, $a_{\mathrm{LiCl}}$, has been calculated from the following equation:

$$
a_{\mathrm{LiCl}}=\frac{m_{\mathrm{LiCl}}}{m^{0}} \gamma_{ \pm}
$$

where the $\mathrm{LiCl}$ molality, $m_{\mathrm{LiCl}}$, is defined as $\mathrm{mol} \mathrm{LiCl} / \mathrm{kg} \mathrm{H}_{2} \mathrm{O}$ and $\mathrm{m}^{0}$ is the standard LiCl molality $\left(\mathrm{m}^{0}=1 \mathrm{~mol} \mathrm{LiCl} / \mathrm{kg} \mathrm{H} \mathrm{H}_{2} \mathrm{O}\right)$. Activity coefficients and osmotic coefficients have been obtained from the literature [61], as well as density values of $\mathrm{LiCl}$ aqueous electrolytes used to transform molality to molarity [66].

Figure 12a shows the $i_{p h}-U$ curves of the sample anodized at $500 \mathrm{rpm}$ and immersed in several concentrated $\mathrm{LiCl}$ electrolytes. It can be observed that $i_{p h}$ values decreased to some extent as the $\mathrm{LiCl}$ concentration increased, as it was also observed in Figure 10a. This fact may be explained by some negative interaction between chlorides and $\mathrm{WO}_{3}$, taking into account that activity of $\mathrm{Cl}^{-}$anions sharply increased for $\mathrm{LiCl}$ concentrations higher than 5M (Figure 11). On the other hand, in spite of the lower photocurrent density values, it is evident that $\mathrm{WO}_{3}$ nanostructures became more stable as $\mathrm{LiCl}$ concentration increased (Figure 12b and Figure 12c), due to the reduction of $a_{w}$, as explained above: in the $5 \mathrm{M} \mathrm{LiCl}$ electrolyte, $a_{w}=0.7$, while in the $13.3 \mathrm{M} \mathrm{LiCl}$ solution $a_{w}=0.1$, so the generation of $\mathrm{H}_{2} \mathrm{O}_{2}$ and hydroxyl radicals via eq. (16) and eq. (17), 
respectively, was significantly reduced in the most concentrated $\mathrm{LiCl}$ electrolyte, this reduction positively affecting the stability of the samples.

Nonetheless, and despite the better performance of $\mathrm{WO}_{3}$ nanostructures in low $a_{W}$ electrolytes in terms of its photodegradation resistance, photocurrent density values obtained from the $i_{p h^{-}} U$ curves were appreciably lower in highly concentrated $\mathrm{Cl}^{-}$ solutions than, for example, in $0.1 \mathrm{M} \mathrm{H}_{2} \mathrm{SO}_{4}$. In consequence, the next step was to keep the values of $a_{W}$ low, thus ensuring the good stability of the samples, but to increase at the same time photocurrent densities. The ability of alcohols to reduce the activity of water is well known $[67,68]$. On the other hand, a high ionic conductivity within the $\mathrm{WO}_{3}$ nanostructures is crucial to prevent uneven current and potential distributions across the nanostructured semiconductor electrode [38], which would negatively affect its photoelectrochemical performance. Methanol possesses an electrical conductivity higher than other alcohols [69] and, as it has been observed above (Figure 9), the role of methanol as a hole scavenger resulted in a considerable increase in photocurrent density due to the direct injection of an electron to the $\mathrm{WO}_{3}$ conduction band (eq. (14)). In that sense, $a_{W}$ has been reduced by adding different amounts of $\mathrm{CH}_{3} \mathrm{OH}$ to a $5 \mathrm{M} \mathrm{LiCl}$ aqueous electrolyte: 4 mol\% $\mathrm{CH}_{3} \mathrm{OH}\left(1 \mathrm{M} ; a_{W} \approx 0.7\right), 36 \mathrm{~mol} \% \mathrm{CH}_{3} \mathrm{OH}\left(a_{W} \approx 0.5\right), 65$ mol\% $\mathrm{CH}_{3} \mathrm{OH}\left(a_{W} \approx 0.3\right)$, water-free $\mathrm{CH}_{3} \mathrm{OH}$ solution $\left(a_{W} \approx 0\right)$. Activity of water values in these solutions have been estimated from the literature [67, 68], taking the values of $a_{W}$ shown in Figure 11 for aqueous $\mathrm{LiCl}$ solutions as starting point. In the $i_{p h^{-}} U$ curves for the different $\mathrm{CH}_{3} \mathrm{OH}-\mathrm{LiCl}$ electrolytes (Figure 13a) it can be observed that photocurrent densities increased as the mol\% of $\mathrm{CH}_{3} \mathrm{OH}$ increased, except for the waterfree $\mathrm{CH}_{3} \mathrm{OH}$ solution, in which $i_{p h}$ took the lowest values of the series. Moreover, photocurrent densities were considerably higher than those obtained in $\mathrm{LiCl}$ aqueous 
solutions (Figure 12a), which can be explained by the additional electron injected in the $\mathrm{WO}_{3}$ valence band during the oxidation of the adsorbed intermediate radical, - $\mathrm{CH}_{2} \mathrm{OH}(\mathrm{ads})$ (eq. (14)). In the water-free $\mathrm{CH}_{3} \mathrm{OH}$ solution, the decrease observed in $i_{p h}$ was most likely due to a decrease in the ionic conductivity of the solution (the conductivity of water-free $5 \mathrm{M} \mathrm{LiCl} /$ methanol is $11.89 \mathrm{mS} \mathrm{cm}^{-1}$, while that of $5 \mathrm{M}$ $\mathrm{LiCl} / 65 \mathrm{~mol} \%$ methanol/water is $22.6 \mathrm{mS} \mathrm{cm}^{-1}$ ).

Concerning the stability of the $\mathrm{WO}_{3}$ nanostructures immersed in these electrolytes, an increase in the mol\% of $\mathrm{CH}_{3} \mathrm{OH}$ increased the resistance of the samples to photodegradation, since the decrease (in $\%$ ) of $i_{p h}$ in $1 \mathrm{~h}$ was manifestly reduced to a value below $10 \%$ in the 65 mol\% $\mathrm{CH}_{3} \mathrm{OH}$ solution; in the water-free $\mathrm{CH}_{3} \mathrm{OH}$ solution $i_{p h}$ even increased in 5.3\%, although photocurrent densities were lower than in the 65 mol\% $\mathrm{CH}_{3} \mathrm{OH}$ solution. These results confirm the beneficial influence that a reduction in $a_{W}$ had on the resistance of the $\mathrm{WO}_{3}$ nanostructures to undergo $\mathrm{H}_{2} \mathrm{O}_{2}$-driven photodegradation. Moreover, the reduction in $a_{W}$ achieved by adding $\mathrm{CH}_{3} \mathrm{OH}$ to the $5 \mathrm{M}$ $\mathrm{LiCl}$ solution avoided the negative effect that elevated chloride activities had on the photoelectrochemical performance of the samples, without leading to an excessive decrease in ionic conductivity, due to the high concentration of $\mathrm{LiCl}$.

\subsection{Photoelectrochemical activity}

Photocatalytic $\mathrm{H}_{2}$ production from methanol-containing solutions has previously been reported in the literature $[54,70-73]$. In these cases, $\mathrm{H}_{2}$ was the main gaseous product evolving on the cathode, while $\mathrm{CO}_{2}$ evolved on the anode after more or less prolonged irradiation due to the complete oxidation of $\mathrm{CH}_{3} \mathrm{OH}[54,71]$. The direct oxidation of 
methanol by surface holes starts with eq. (13) and eq. (14) and continues as follows [54]:

$$
\begin{gathered}
\mathrm{CH}_{2} \mathrm{O}(\text { ads })+\mathrm{h}^{+} \rightarrow \mathrm{CHO} \cdot(\text { ads })+\mathrm{H}^{+} \\
\mathrm{CHO} \cdot(\text { ads })+\mathrm{h}^{+}+\mathrm{H}_{2} \mathrm{O} \rightarrow \mathrm{CHOOH}(\text { ads })+\mathrm{H}^{+} \\
\mathrm{CHOOH}(\text { ads })+\mathrm{h}^{+} \rightarrow \mathrm{CHOO} \cdot(\text { ads })+\mathrm{H}^{+} \\
\mathrm{CHOO} \cdot(\text { ads })+\mathrm{h}^{+} \rightarrow \mathrm{CO}_{2}(\text { ads })+\mathrm{H}^{+}
\end{gathered}
$$

The complete oxidation of methanol via eqs. (13), (14), (20)-(23) involves the formation of $6 \mathrm{H}^{+}$per mol of $\mathrm{CH}_{3} \mathrm{OH}$, so the cathodic reaction is:

$$
6 \mathrm{H}^{+}+6 \mathrm{e}^{-} \rightarrow 3 \mathrm{H}_{2}(\mathrm{~g})
$$

And the overall reaction is:

$$
\mathrm{CH}_{3} \mathrm{OH}+\mathrm{H}_{2} \mathrm{O} \rightarrow \mathrm{CO}_{2}(\mathrm{~g})+3 \mathrm{H}_{2}(\mathrm{~g})
$$

These overall methanol decomposition has a lower splitting energy than water $(0.7 \mathrm{eV}$ vs. $1.23 \mathrm{eV}$ ) [72]. In a recent work by Lin et. al [72], it was observed that the maximum hydrogen production using a $\mathrm{Pt} / \mathrm{TiO}_{2-\mathrm{x}} \mathrm{N}_{\mathrm{x}}$ catalyst was achieved in a solution 80 vol\% of methanol, which corresponds approximately to a $65 \mathrm{~mol}^{2} \mathrm{CH}_{3} \mathrm{OH}$. Hence, in concentrated methanolic aqueous solutions, the photogeneration of $\mathrm{H}_{2}$ seems to be enhanced, while $\mathrm{CO}_{2}$ evolves on the anode. In the present case, where the methanol/water solution also has $5 \mathrm{M} \mathrm{LiCl}$, gaseous $\mathrm{Cl}_{2}$, as well as some $\mathrm{O}_{2}$, may also form on the anode. 
Figure 14 shows the $i_{p h^{-}} U$ curves and the photocurrent density transients recorded for 1 hour under simulated sunlight of the different $\mathrm{WO}_{3}$ samples anodized at various rotation velocities, immersed in the $5 \mathrm{M} \mathrm{LiCl}$ with $65 \mathrm{~mol} \% \mathrm{CH}_{3} \mathrm{OH}$ electrolyte. It can be observed that the relationship between photocurrent density values and rotation velocity is not direct. The sample anodized at $375 \mathrm{rpm}$ provided the highest photoresponse, which is consistent with this sample having the largest electrochemically active surface area. This sample was followed by those synthesized at 250, 500 and $750 \mathrm{rpm}$ (in that order), which also presented high photocurrent densities, while the photoresponse of the samples anodized at 125 and $1000 \mathrm{rpm}$ was significantly lower. Finally, the $\mathrm{WO}_{3}$ nanoplatelets formed under static flow conditions $(0 \mathrm{rpm})$ provided the lowest photocurrent density. These results are consistent with the previous findings, since samples synthesized at low (0 and $125 \mathrm{rpm})$ and high $(1000 \mathrm{rpm})$ rotation velocities presented lower electrochemically active surface areas and higher charge-transfer resistance values than those anodized at intermediate rpm (250-500 rpm).

Figure 15 shows the $\left(i_{p h} h v\right)^{0.5}$ vs. $h v$ plots for the different samples obtained by measuring the photocurrent density of the $\mathrm{WO}_{3}$ nanoplatelets at an applied potencial of $1.02 \mathrm{~V}_{\mathrm{Ag} / \mathrm{AgCl}}$ in the wavelength range from 300 to $500 \mathrm{~nm}$. These plots have been used to determine the indirect band-gap energy $\left(E_{g}\right)$ of the nanostructures, where $h$ is Planck's constant $\left(4.1357 \times 10^{-15} \mathrm{eV} \cdot \mathrm{s}\right)$ and $v$ is the frequency of light. The $E_{g}$ values, obtained from the x-intercept of the extrapolated linear part of the diagram, are shown in Table 2. The calculated $E_{g}$ are slightly lower than the typical value for crystalline $\mathrm{WO}_{3}(2.6 \mathrm{eV})[6]$. This slight red shift can be explained by an enhancement in light scattering due to the nanoplatelet morphology resulting in higher light adsorption by the 
nanostructures [30]. No appreciable differences in $E_{g}$ were observed for samples anodized at different rotation velocities.

\section{CONCLUSIONS}

Globular clusters of $\mathrm{WO}_{3}$ nanoplatelets associated in a tree-like fashion have been obtained by anodizing $\mathrm{W}$ in an acidic F-containing electrolyte under controlled hydrodynamic conditions. The thickest nanoplatelets layers were obtained at $375 \mathrm{rpm}$, since this rotation velocity was high enough to enhance mass transfer towards the electrode surface and hence to increase the formation of soluble species and their subsequent precipitation in the form of hydrated $\mathrm{WO}_{3}$, but it was not too high as to facilitate the removal of these soluble species from the electrode surrounding area.

The charge-transfer resistance at the nanostructure/electrolyte interface decreased for the samples anodized at intermediate rotation velocities $(250-500 \mathrm{rpm})$, while the double layer capacitance increased for these samples, which can be explained by an increase of their electrochemically active surface area.

Mott-Schottky analysis concluded that tree-like $\mathrm{WO}_{3}$ nanoplatelets synthesized at intermediate rotation velocities (250-500 rpm) had the highest concentration of oxygen vacancies in their crystalline structures, resulting in higher electrical conductivities, which is consistent with the decrease in the charge-transfer resistance observed through EIS measurements. 
$\mathrm{WO}_{3}$ nanostructures were not stable in alkaline media due to the active dissolution of the oxide by the action of $\mathrm{OH}^{-}$. Moreover, these nanostructures were not resistant to photodegradation in aqueous acidic electrolytes with low ionic strengths due to the photogeneration of peroxides and hydroxyl radicals that interacted with the surface of the electrode and resulted in a gradual loss of photoactivity. In highly concentrated chloride solutions the stability of the samples manifestly improved due to the reduction of the activity of water, which led to a decrease in the formation of peroxides and hydroxyl radicals. However, the photoactivity of the samples decreased with increasing chloride activity, so aqueous/methanolic mixed solutions with high chloride concentration were used in the end to assure a very good photostability of the samples.

Apart from being a hole scavenger and helping in the separation of photogenerated electron-hole pairs, methanol has been demonstrated to play an important role in reducing the activity of water and thus the $\mathrm{H}_{2} \mathrm{O}_{2}$-induced photodegradation of $\mathrm{WO}_{3}$ nanoplatelets. The suppression of peroxide species remarkably improved the long-term photostability of $\mathrm{WO}_{3}$.

Photocurrent densities measured indicated the superior photocatalytic activity of treelike $\mathrm{WO}_{3}$ nanoplatelets synthesized at intermediate rotation velocities, especially at 375 rpm, which was attributed to their higher efficiency for electron transfer due to their larger surface area. These results indicate that photoelectrochemical efficiency of $\mathrm{WO}_{3}$ nanoplatelets can be largely enhanced simply by anodizing W under controlled hydrodynamic conditions at a rotation velocity of $375 \mathrm{rpm}$. 
Acknowledgements: Authors would like to express their gratitude for the financial support to the Ministerio of Economía y Competitividad (Project CTQ2013-42494-R) and for its help in the Laser Raman Microscope acquisition (UPOV08-3E-012).

\section{REFERENCES}

[1] H. E. Prakasam, K. Shankar, M. Paulose, O. K. Varghese, C. A. Grimes, J. Phys. Chem. C 111 (2007) 7235-7241.

[2] P. Roy, S. Berger, P. Schmuki, Angew. Chem. Int. Ed. 50 (2011) 2904-2939.

[3] R. Sánchez-Tovar, R. M. Fernández-Domene, D. M. García-García, J. GarcíaAntón, J. Power Sources 286 (2015) 224-231.

[4] H. Tsuchiya, J. M. Macak, I. Sieber, L. Taveira, A. Ghicov, K. Sirotna, P. Schmuki, Electrochem. Commun. 7 (2005) 295-298.

[5] E. Widenkvist, R. A. Quinlan, B. C. Holloway, H. Grennberg, U. Jansson, Cryst. Growth Des. 8 (2008) 3750-3753.

[6] H. Zheng, J. Z. Ou, M. S. Strano, R. B. Kaner, A. Mitchell, K. Kalantar-zadeh. Nanostructured Tungsten Oxide - Properties, Synthesis, and Applications, Adv. Funct. Mater. 21 (2011) 2175-2196.

[7] V. Chakrapani, J. Thangala, M. K. Sunkara, Int. J. Hydrogen Energ. 34 (2009) 9050-9059.

[8] V. Cristino, S. Caramori, R. Argazzi, L. Meda, G. L. Marra, C. A. Bignozzi, Langmuir 27 (2011) 7276-7284.

[9] F. Amano, M. Tian, B. Ohtani, A. Chen, J. Solid State Electrochem. 16 (2012) 1965-1973.

[10] Q. Chen, J. Li, B. Zhou, M. Long, H. Chen, Y. Liu, W. Cai, W. Shangguan, Electrochem. Commun. 20 (2012) 153-156.

[11] S. M. Ahmed, J. Leduc, S. F. Haller, J. Phys. Chem. 92 (1988) 6655-6660.

[12] K. Sivula, F. Le Formal, M. Grätzel, ChemSusChem 4 (2011) 432-449.

[13] S. J. Kim, J. Choi, Electrochem. Commun. 10 (2008) 175-179.

[14] J. Zhao, X. Wang, J. Liu, Y. Meng, X. Xu, C. Tang, Mater. Chem. Phys. 126 (2011) 555-559. 
[15] T. Bak, J. Nowotny, M. Rekas, C. C. Sorrell, Int. J. Hydrogen Energ. 27 (2002) 991-1022.

[16] S. Chen, L.-W. Wang, Chem. Mater. 24 (2012) 3659-3666.

[17] A. Watcharenwong, W. Chanmanee, N. R. de Tacconi, C. R. Chenthamarakshan, P. Kajitvichyanukul, K. Rajeshwar, J. Electroanal. Chem. 612 (2008) 112-120.

[18] A. Z. Sadek, H. Zheng, M. Breedon, V. Bansal, S. K. Bhargava, K. Latham, J. Zhu, L. Yu, Z. Hu, P. G. Spizzirri, W. Wlodarski, K. Kalantar-zadeh, Langmuir 25 (2009) 9545-9551.

[19] H. Zheng, A. Z. Sadek, K. Latham, K. Kalantar-zadeh, Electrochem. Commun. 11 (2009) 768-771.

[20] K. Kalantar-zadeh, A. Z. Sadek, H. Zheng, V. Bansal, S. K. Bhargava, W. Wlodarski, J. Zhu, L. Yu, Z. Hu, Sensor. Actuat. B-Chem. 142 (2009) 230235 .

[21] W. Lee, D. Kim, K. Lee, P. Roy, P. Schmuki, Electrochim. Acta 56 (2010) 828-833.

[22] Y. Liu, Y. Li, W. Li, S. Han, C. Liu, Appl. Surf. Sci. 258 (2012) 5038-5045.

[23] C. W. Lai, S. Sreekantan, Mat. Sci. Semicon. Proc. 16 (2013) 303-310.

[24] C. K. Wang, C. K. Lin, C. L. Wu, S. C. Wang, J. L. Huang, Electrochim. Acta $112(2013)$ 24-31.

[25] C. Ng, Y. H. Ng, A. Iwase, R. Amal, ACS Appl. Mater. Inter. 5 (2013) 52695275 .

[26] K. R. Reyes-Gil, C. Wiggenhorn, B. S. Brunschwig, N. S. Lewis, J. Phys. Chem. C 117 (2013) 14947-14957.

[27] W. Li, P. Da, Y. Zhang, Y. Wang, X. Lin, X. Gong, G. Zheng, ACS Nano 8 (2014) 11770-11777.

[28] J. H. Ha, P. Muralidharan, D. K. Kim, J. Alloy. Compd. 475 (2009) 446-451.

[29] C. Ng, C. Ye, Y. H. Ng, R. Amal, Cryst. Growth Des. 10 (2010) 3794-3801.

[30] J. Yang, W. Li, J. Li, D. Sun, Q. Chen, J. Mater. Chem. 22 (2012) 1774417752.

[31] S. S. Kalanur, Y. J. Hwang, S. Y. Chae, O. S. Joo, J. Mater. Chem. A 1 (2013) 3479-3488.

[32] M. Anik, T. Cansizoglu, J. Appl. Electrochem. 36 (2006) 603-608.

[33] C. A. Bignozzi, S. Caramori, V. Cristino, R. Argazzi, L. Meda, A. Tacca, Chem. Soc. Rev. 42 (2013) 2228-2246. 
[34] J. M. Spurgeon, J. M. Velazquez, M. T. McDowell, Phys. Chem. Chem. Phys. 16 (2014) 3623-3631.

[35] W. Li, J. Li, X. Wang, J. Ma, Q. Chen, Int. J. Hydrogen Energ. 35 (2010) $13137-13145$.

[36] M. Yagi, S. Maruyama, K. Sone, K. Nagai, T. Norimatsu, J. Solid State Chem. 181 (2008) 175-182.

[37] J. A. Seabold, K. S. Choi, Chem. Mater. 23 (2011) 1105-1112.

[38] R. Solarska, R. Jurczakowski, J. Augustynski, Nanoscale 4 (2012) 1553-1556.

[39] R. M. Fernández-Domene, R. Sánchez-Tovar, E. Segura-Sanchís, J. GarcíaAntón, Chem. Eng. J. 286 (2016) 59-67.

[40] J. Z. Ou, M. Z. Ahmad, K. Latham, K. Kalantar-zadeh, G. Sberveglieri, W. Wlodarski, Procedia Engineering 25 (2011) 247-251.

[41] W. Li, J. Li, X. Wang, S. Luo, J. Xiao, Q. Chen, Electrochim. Acta 56 (2010) 620-625.

[42] A. Di Paola, F. Di Quarto, C. Sunseri, Corros. Sci. 20 (1980) 1067-1078.

[43] A. J. Bard and L. R. Faulkner, Electrochemical Methods: Fundamentals and Applications, John Wiley \& Sons, New York, NY, 2001.

[44] G. J. Brug, A. L. G. van den Eeden, M. Sluyters-Rehbach, J. H. Sluyters, J. Electroanal. Chem. 176 (1984) 275-295.

[45] B. Hirschorn, M. E. Orazem, B. Tribollet, V. Vivier, I. Frateur, M. Musiani, Electrochim. Acta 55 (2010) 6218-6227.

[46] J. O. Bockris, J. Appl. Phys. 52 (1981) 808-810.

[47] K. Uosaki, H. Kita, J. Electrochem. Soc. 130 (1983) 895-897.

[48] R. M. Fernández-Domene, E. Blasco-Tamarit, D. M. García-García, J. GarcíaAntón, Electrochim. Acta 95 (2013) 1-11.

[49] G. Wang, Y. Ling, H. Wang, X. Yang, C. Wang, J. Z. Zhang, Y. Li, Energy Environ. Sci. 5 (2012) 6180-6187.

[50] C. R. Lhermitte, J. G. Verwer, B. M. Bartlett, J. Mater. Chem. A DOI: 10.1039/C5TA04747A (2016) .

[51] R. van de Krol, Principles of Photoelectrochemical Cells, in: R. van de Krol, M. Grätzel (eds.), Photoelectrochemical Hydrogen Production, New York, 2012.

[52] A. Hagfeldt, H. Lindström, S. Södergren, S. E. Lindquist, J. Electroanal. Chem. 381 (1995) 39-46. 
[53] C. Santato, M. Ulmann, J. Augustynski, J. Phys. Chem. B 105 (2001) 936-940.

[54] J. Chen, D. F. Ollis, W. H. Rulkens, H. Bruning, Wat. Res. 33 (1999) 669-676.

[55] M. Ulmann, N. R. de Tacconi, J. Augustynski, J. Phys. Chem. 90 (1986) 65236530 .

[56] J. C. Hill, K. S. Choi, J. Phys. Chem. C 116 (2012) 7612-7620.

[57] Q. Mi, A. Zhanaidarova, B. S. Brunschwig, H. B. Gray, N. S. Lewis, Energy Environ. Sci. 5 (2012) 5694-5700.

[58] J. Zhao, E. Olide, F. E. Osterloh, J. Electrochem. Soc. 162 (2015) H65-H71.

[59] L. Weinhardt, M. Blum, M. Bär, C. Heske, B. Cole, B. Marsen, E. L. Miller, J. Phys. Chem. C 112 (2008) 3078-3082.

[60] Q. Mi, R. H. Coridan, B. S. Brunschwig, H. B. Gray, N. S. Lewis, Energy Environ. Sci. 6 (2013) 2646-2653.

[61] W. J. Hamer, Y.-C. Wu, J. Phys. Chem. Ref. Data 1 (1972) 1047-1075.

[62] K. S. Pitzer, J. C. Peiper, R. H. Busey, J. Phys. Chem. Ref. Data 13 (1984) 1102.

[63] J. M. Prausnitz, R. N. Lichtenthaler, and E. G. Azevedo, Molecular Thermodynamics of Fluid-Phase Equilibria, Prentice Hall, Upper Saddle River, NJ, 1999.

[64] M. J. Blandamer, J. B. F. N. Engberts, P. T. Gleeson, J. C. R. Reis, Chem. Soc. Rev. 34 (2005) 440-458.

[65] C. Held, L. F. Cameretti, G. Sadowski, Fluid Phase Equilibria 270 (2008) 8796.

[66] I. M. Abdulagatov, N. D. Azizov, Chem. Geol. 230 (2006) 22-41.

[67] P. S. Crozier, R. L. Rowley, Fluid Phase Equilibr. 193 (2002) 53-73.

[68] G. C. Nihous, C. K. Kinoshita, S. M. Masutani, Chem. Eng. Sci. 64 (2009) 2767-2771.

[69] M. Prego, O. Cabeza, E. Carballo, C. F. Franjo, E. Jiménez, J. Mol. Liq. 89 (2000) 233-238.

[70] J. Chen, D. F. Ollis, W. H. Rulkens, H. Bruning, Wat. Res. 33 (1999) 661-668.

[71] T. Kawai, T. Sakata, J. Chem. Soc. Chem. Comm. (1980) 694-695.

[72] W. C. Lin, W. D. Yang, I. L. Huang, T. S. Wu, Z. J. Chung, Energ. Fuel 23 (2009) 2192-2196.

[73] A. Galinska, J. Walendziewski, Energ. Fuel 19 (2005) 1143-1147. 


\section{Tables captions}

Table 1. Donor density $\left(N_{D}\right)$ and flat-band potential $\left(U_{F B}\right)$ of the $\mathrm{WO}_{3}$ nanoplatelets formed at different rotation velocities.

Table 2. Band-gap values of the $\mathrm{WO}_{3}$ nanoplatelets formed at different rotation velocities.

\section{Figures captions}

Figure 1. FE-SEM images of the $\mathrm{WO}_{3}$ nanostructures formed upon anodization of $\mathrm{W}$ in a $1.5 \mathrm{M} \mathrm{H}_{2} \mathrm{SO}_{4}+0.1 \mathrm{M} \mathrm{NaF}$ electrolyte at $50^{\circ} \mathrm{C}$, imposing a potential of $20 \mathrm{~V}$ for 4 hours, under different hydrodynamic conditions: (a) $0 \mathrm{rpm}$, (b) $125 \mathrm{rpm}$, (c) $250 \mathrm{rpm}$, (d) $375 \mathrm{rpm}$, (e) $500 \mathrm{rpm}$, (f) $750 \mathrm{rpm}$, and (g) $1000 \mathrm{rpm}$.

Figure 2. Nanoplatelets layer thickness and \% of covered surface as a function of the rotation velocity (a). FE-SEM cross-sectional images of samples anodized at $0 \mathrm{rpm}$ (left) and $500 \mathrm{rpm}$ (right).

Figure 3. Current density transient recorded during anodization for all the samples.

Figure 4. Experimental Nyquist (a) and Bode-phase (b) diagrams for the $\mathrm{WO}_{3}$ nanoplatelets formed at different rotation velocities.

Figure 5. Electrical equivalent circuits used to simulate the experimental EIS data for the $\mathrm{WO}_{3}$ nanoplatelets formed at (a) 0,125, 250 and $375 \mathrm{rpm}$; (b) 500, 750 and 1000 rpm.

Figure 6. Values of the charge-transfer resistance $\left(R_{\text {nano }}\right)$ and the double layer capacitance $\left(C_{\text {nano }}\right)$ of the $\mathrm{WO}_{3}$ nanoplatelets formed at different rotation velocities. 
Figure 7. Mott-Schottky plots for the $\mathrm{WO}_{3}$ nanoplatelets formed at different rotation velocities.

Figure 8. (a) Photocurrent density $\left(i_{p h}\right)$ vs. potential $(U)$ curves of the $\mathrm{WO}_{3}$ nanostructure formed at $500 \mathrm{rpm}$ measured in $0.1 \mathrm{M} \mathrm{Na}_{2} \mathrm{SO}_{4}, 0.1 \mathrm{M} \mathrm{H} \mathrm{H}_{2} \mathrm{SO}_{4}$ and $0.1 \mathrm{M}$ $\mathrm{KOH}$ solutions under AM1.5 illumination. (b) Photocurrent density transients under illumination obtained at an applied potential of $1.02 \mathrm{~V}_{\mathrm{Ag} / \mathrm{AgCl}}$ in the $0.1 \mathrm{M} \mathrm{Na}_{2} \mathrm{SO}_{4}$ and $0.1 \mathrm{M} \mathrm{H}_{2} \mathrm{SO}_{4}$ electrolytes.

Figure 9. (a) Photocurrent density $\left(i_{p h}\right)$ vs. potential $(U)$ curves of the $\mathrm{WO}_{3}$ nanostructure formed at $500 \mathrm{rpm}$ measured in $0.1 \mathrm{M} \mathrm{H}_{2} \mathrm{SO}_{4}$ and $0.1 \mathrm{M} \mathrm{H}_{2} \mathrm{SO}_{4}+1 \mathrm{M}$ $\mathrm{CH}_{3} \mathrm{OH}$ solutions under AM1.5 illumination. (b) Photocurrent density transients under illumination obtained at an applied potential of $1.02 \mathrm{~V}_{\mathrm{Ag} / \mathrm{AgCl}}$ in the same electrolytes.

Figure 10. (a) Photocurrent density $\left(i_{p h}\right)$ vs. potential $(U)$ curves of the $\mathrm{WO}_{3}$ nanostructure formed at $500 \mathrm{rpm}$ measured in $0.1 \mathrm{M} \mathrm{HCl}, 1 \mathrm{M} \mathrm{HCl}, 3 \mathrm{M} \mathrm{NaCl}, 5 \mathrm{M} \mathrm{NaCl}$ and $1 \mathrm{M} \mathrm{CH} \mathrm{CH}_{3} \mathrm{SO}_{3} \mathrm{H}$ solutions under $\mathrm{AM} 1.5$ illumination. (b) Photocurrent density transients under illumination obtained at an applied potential of $1.02 \mathrm{~V}_{\mathrm{Ag} / \mathrm{AgCl}}$ in the same electrolytes. (c) Values of photocurrent density before and after the stability tests and $\%$ of photocurrent density decrease in the same electrolytes as before.

Figure 11. Variation of activity of chloride ions $\left(a_{L i C l}\right)$ and activity of water $\left(a_{W}\right)$ with the $\mathrm{LiCl}$ molar concentration.

Figure 12. (a) Photocurrent density $\left(i_{p h}\right)$ vs. potential $(U)$ curves of the $\mathrm{WO}_{3}$ nanostructure formed at $500 \mathrm{rpm}$ measured in $5 \mathrm{M} \mathrm{LiCl}, 7.2 \mathrm{M} \mathrm{LiCl}, 9.6 \mathrm{M} \mathrm{LiCl}$ and 13.3M LiCl solutions under AM1.5 illumination. (b) Photocurrent density transients under illumination obtained at an applied potential of $1.02 \mathrm{~V}_{\mathrm{Ag} / \mathrm{AgCl}}$ in the same electrolytes. (c) Values of photocurrent density before and after the stability tests and \% of photocurrent density decrease in the same electrolytes as before. 
Figure 13. (a) Photocurrent density $\left(i_{p h}\right)$ vs. potential $(U)$ curves of the $\mathrm{WO}_{3}$ nanostructure formed at $500 \mathrm{rpm}$ measured in different aqueous/methanolic solutions with 5M LiCl under AM1.5 illumination. (b) Photocurrent density transients under illumination obtained at an applied potential of $1.02 \mathrm{~V}_{\mathrm{Ag} / \mathrm{AgCl}}$ in the same electrolytes. (c) Values of photocurrent density before and after the stability tests and \% of photocurrent density decrease in the same electrolytes as before.

Figure 14. (a) Photocurrent density $\left(i_{p h}\right)$ vs. potential $(U)$ curves of the $\mathrm{WO}_{3}$ nanoplatelets formed at different rotation velocities, measured in a $65 \mathrm{~mol} \% \mathrm{CH}_{3} \mathrm{OH}$ with $5 \mathrm{M} \mathrm{LiCl}$ solution under AM1.5 illumination. (b) Photocurrent density transients under illumination obtained at an applied potential of $1.02 \mathrm{~V}_{\mathrm{Ag} / \mathrm{AgCl}}$ in the same electrolyte.

Figure 15. Band-gap determination for the $\mathrm{WO}_{3}$ nanoplatelets formed at different rotation velocities from the $\left(i_{p h} h v\right)^{0.5}$ vs. $h v$ plots. 


\begin{tabular}{ccc}
\hline Sample $(\mathbf{r p m})$ & $\boldsymbol{N}_{\boldsymbol{D}}\left(\times \mathbf{1 0}^{\mathbf{2 2}} \mathbf{c m}^{\mathbf{- 3}}\right)$ & $\boldsymbol{U}_{\boldsymbol{F B} \boldsymbol{B}} / \mathbf{V}_{\mathbf{A g} / \mathbf{A g C l}}$ \\
\hline 0 & $1.2 \pm 0.3$ & $0.30 \pm 0.07$ \\
125 & $2.4 \pm 0.2$ & $0.29 \pm 0.03$ \\
250 & $49.5 \pm 19.1$ & $0.28 \pm 0.06$ \\
375 & $41.9 \pm 8.1$ & $0.32 \pm 0.07$ \\
500 & $57.3 \pm 13.5$ & $0.23 \pm 0.01$ \\
750 & $14.3 \pm 0.5$ & $0.30 \pm 0.01$ \\
1000 & $10.5 \pm 0.1$ & $0.23 \pm 0.02$ \\
\hline
\end{tabular}


Table 2

\begin{tabular}{cc}
\hline Sample (rpm) & $\boldsymbol{E}_{g} / \mathbf{e V}$ \\
\hline 0 & $2.55 \pm 0.04$ \\
125 & $2.53 \pm 0.03$ \\
250 & $2.49 \pm 0.02$ \\
375 & $2.48 \pm 0.03$ \\
500 & $2.49 \pm 0.04$ \\
750 & $2.53 \pm 0.05$ \\
1000 & $2.52 \pm 0.06$ \\
\hline
\end{tabular}




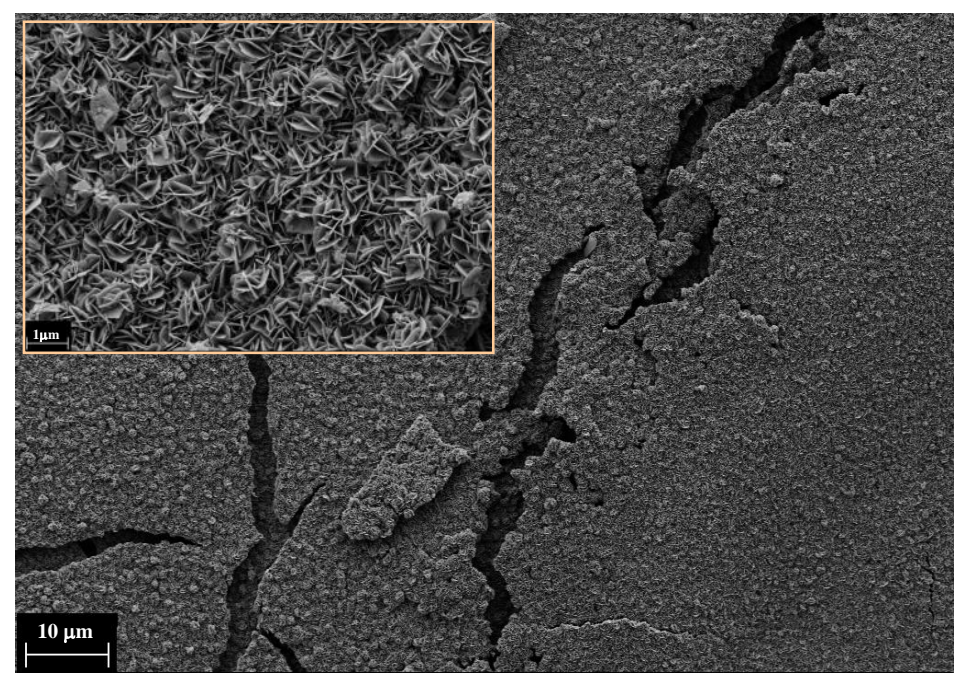

(a)

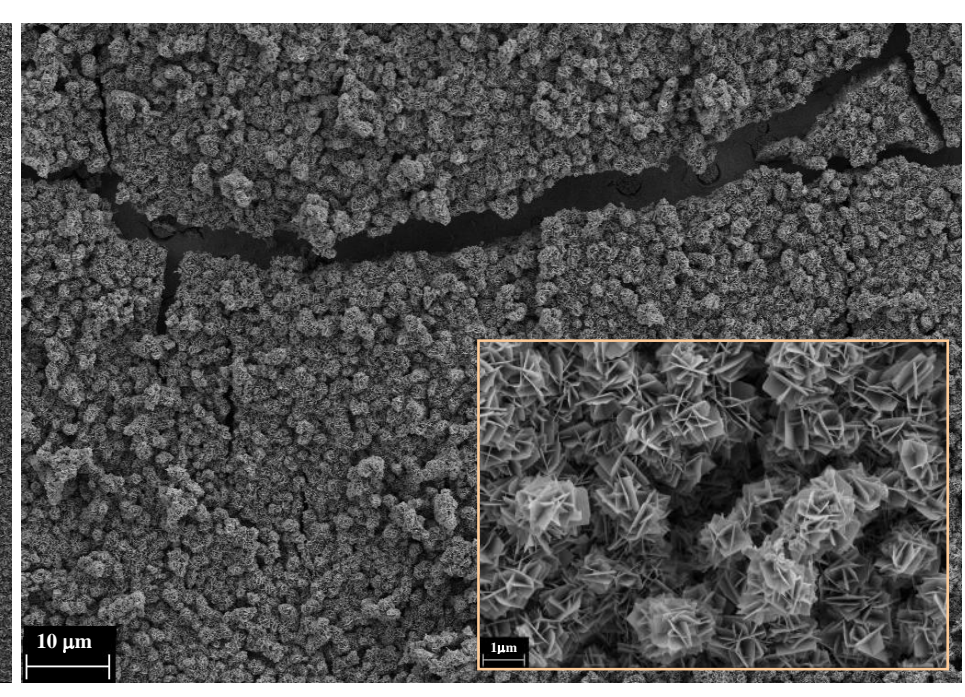

(b)

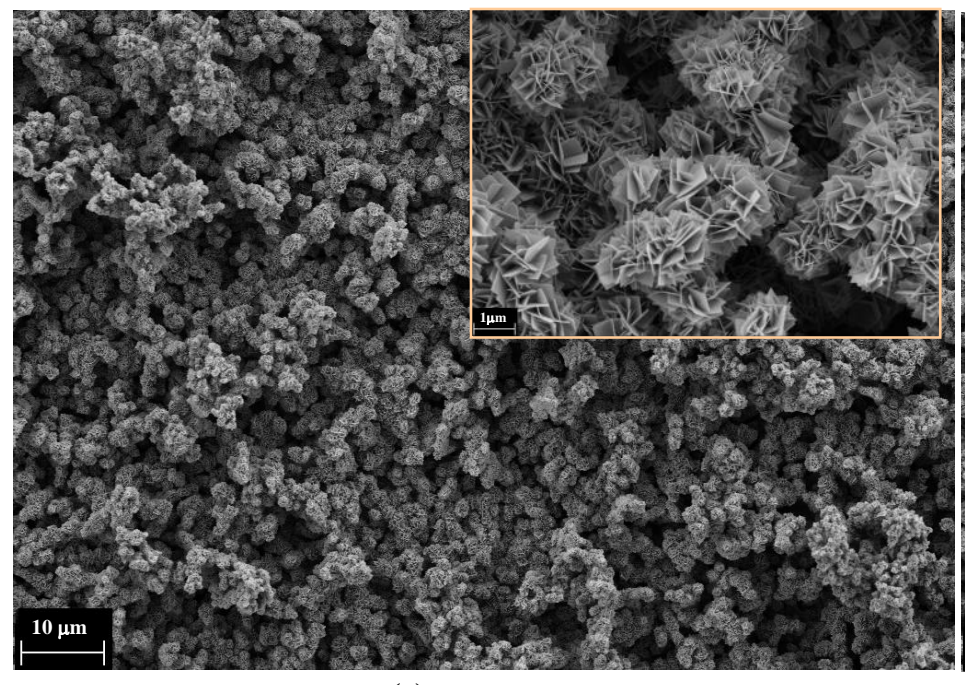

(c)

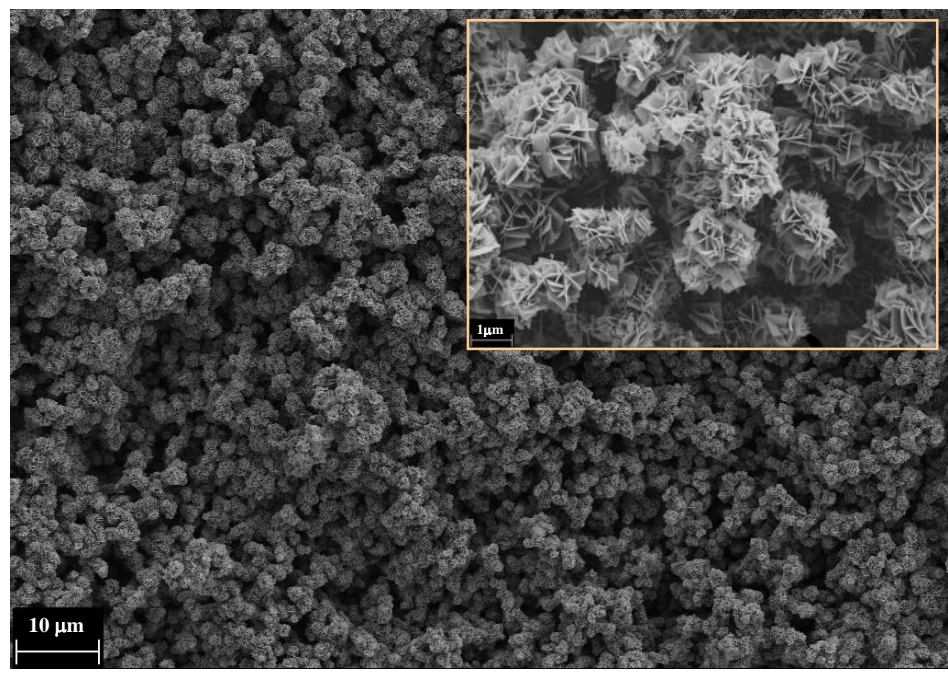

(e)

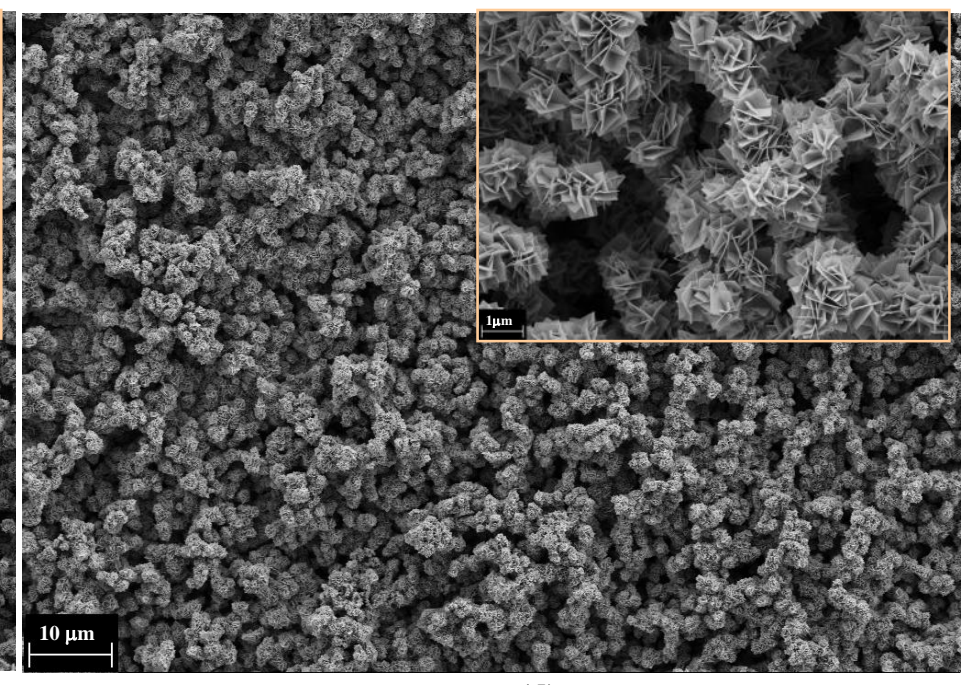

(d)

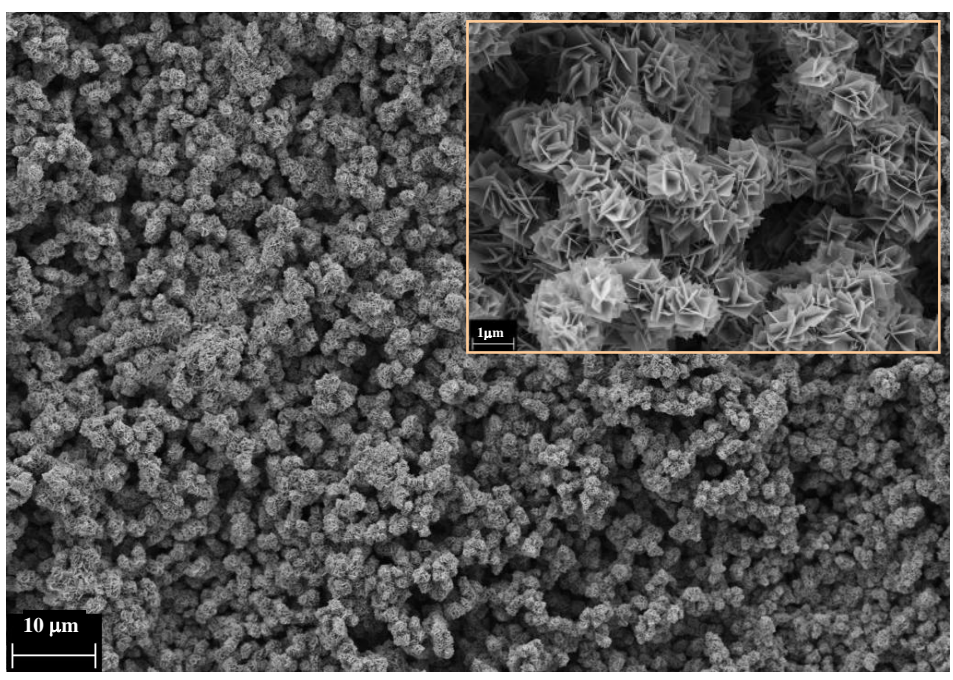

(f) 


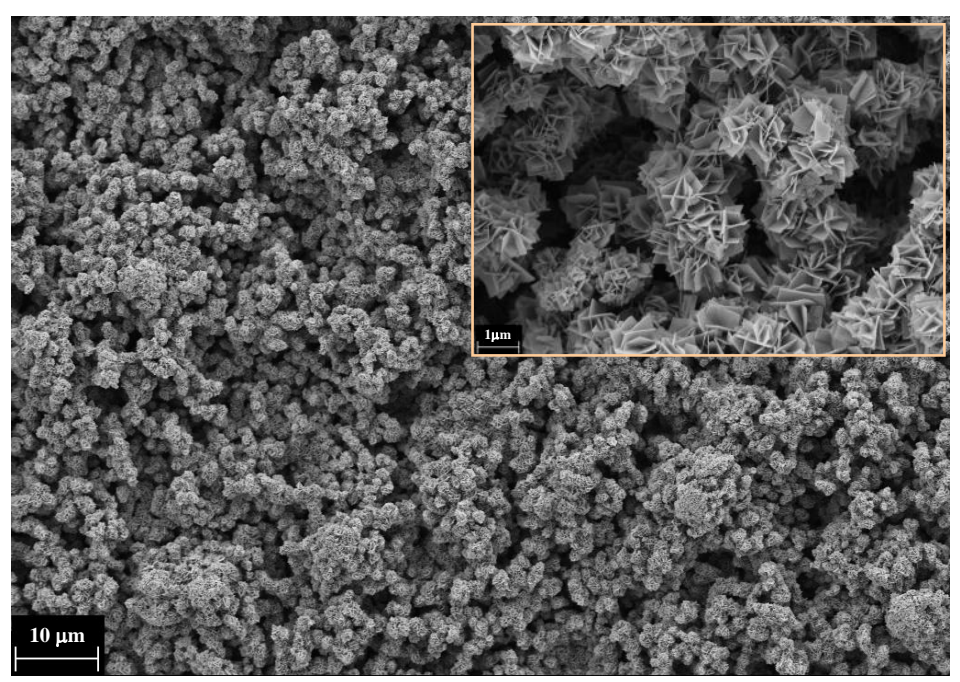

(g) 


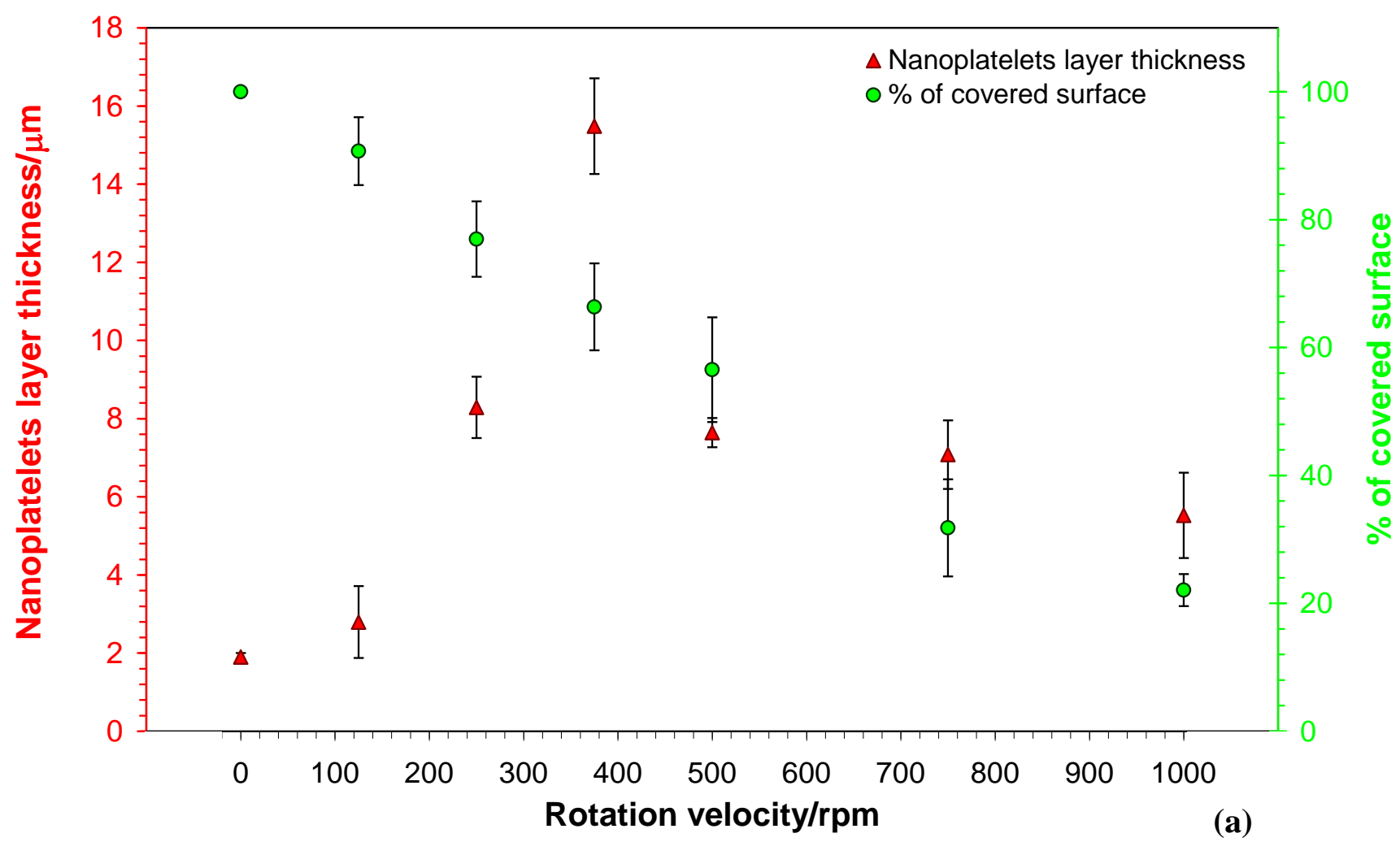

(b)
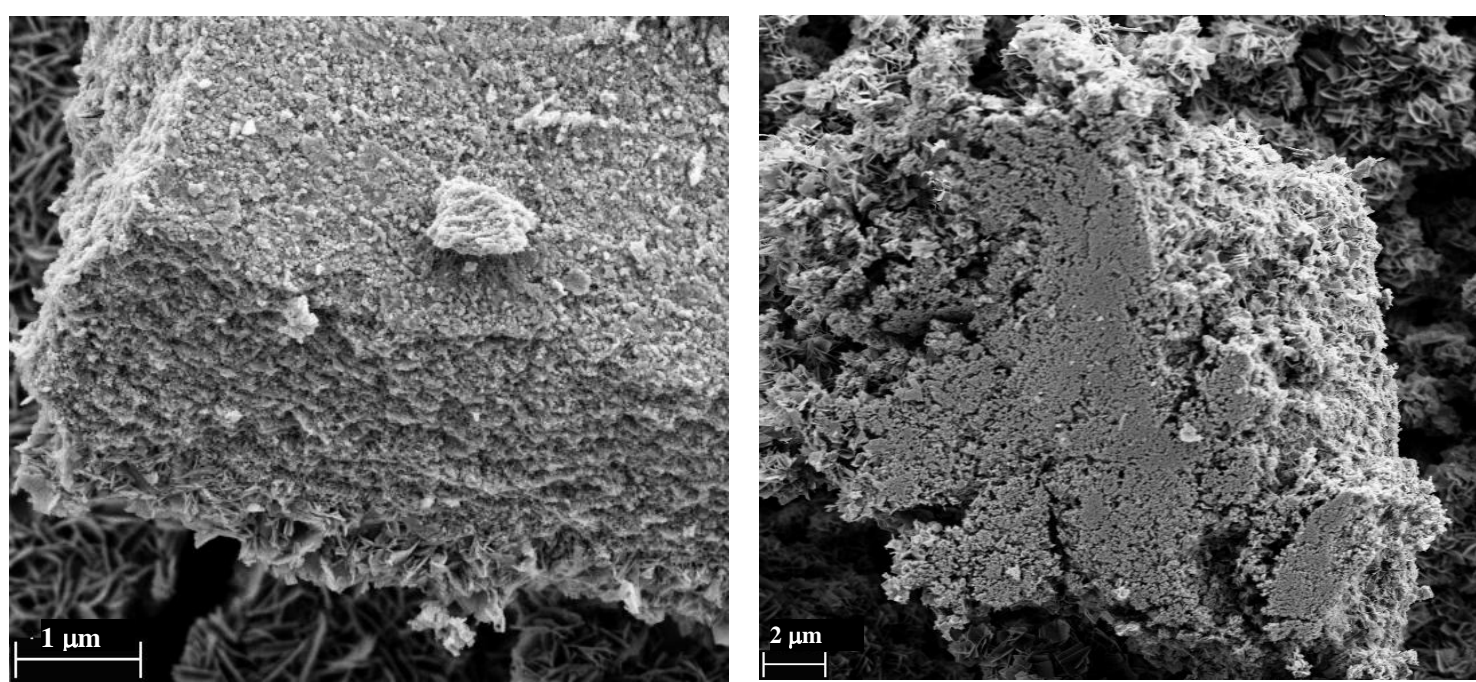
Figure 3

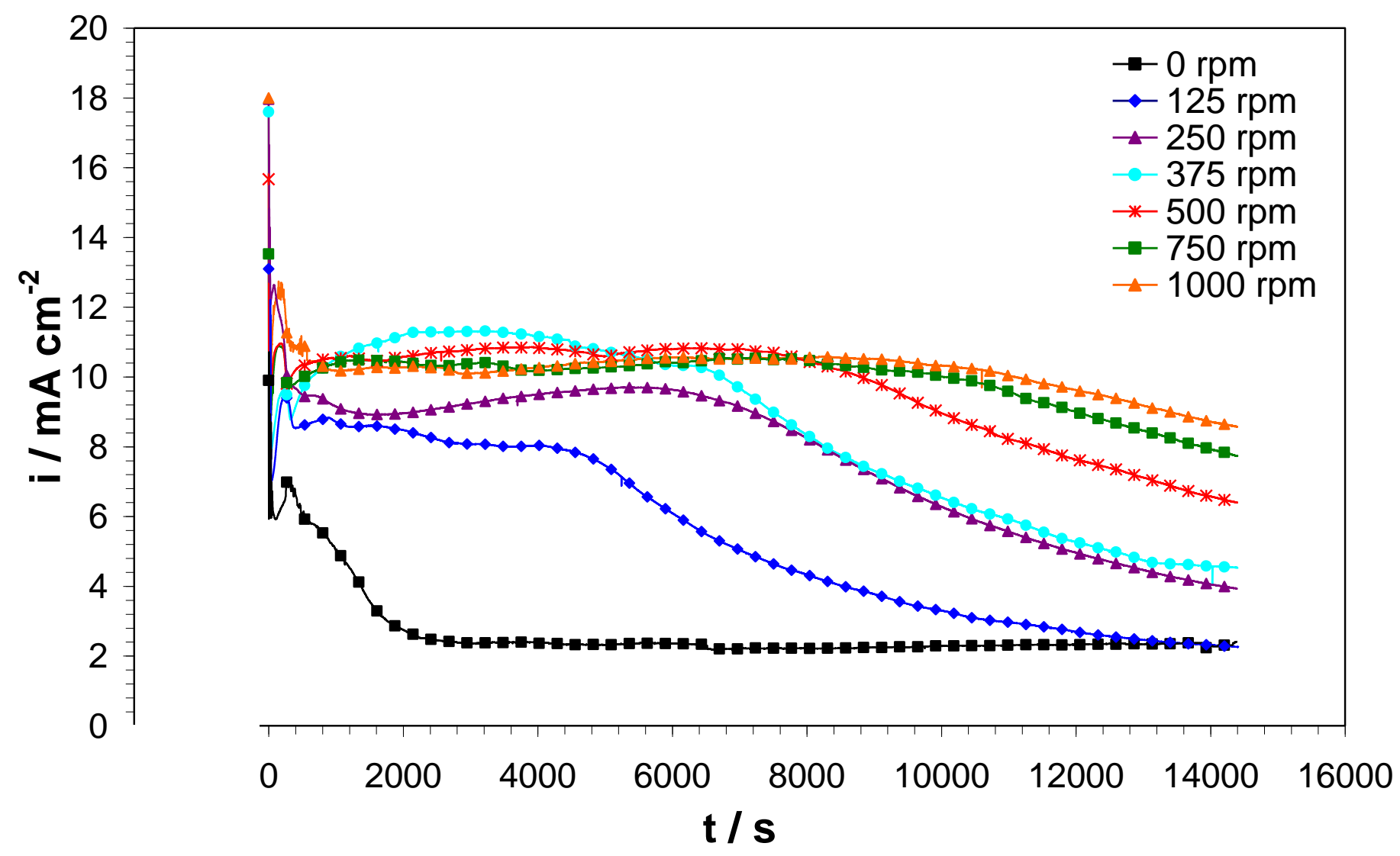



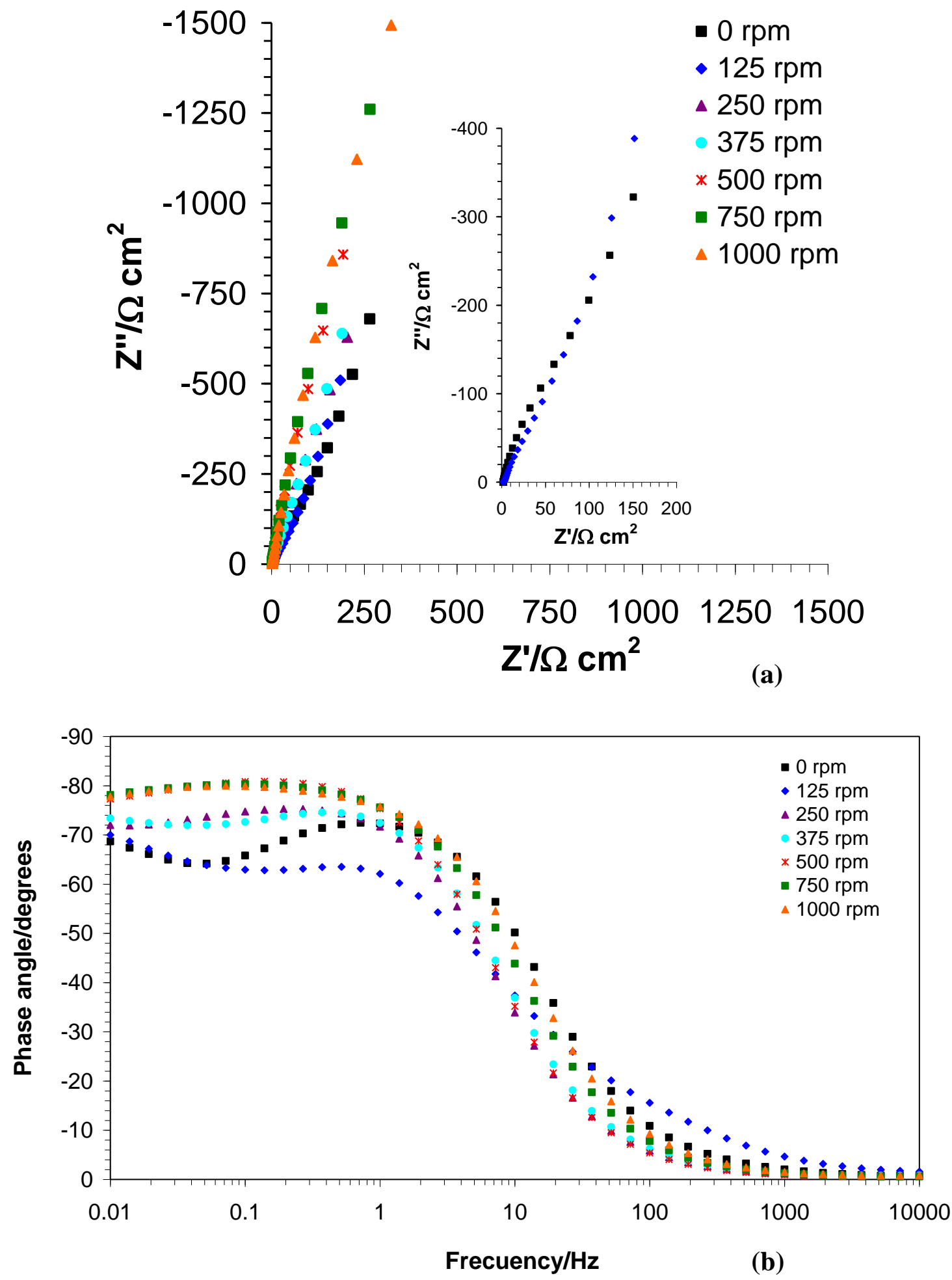

Frecuency/Hz

(b) 
Figure 5

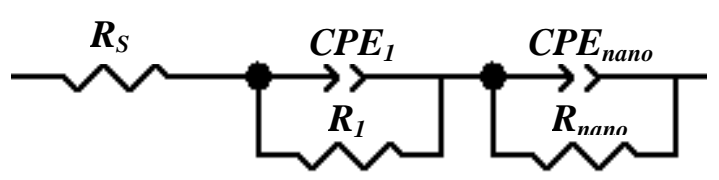

(a)

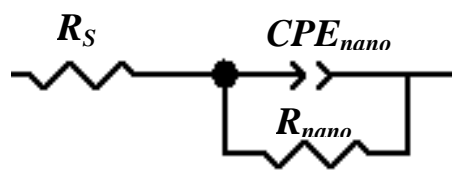

(b) 
Figure 6

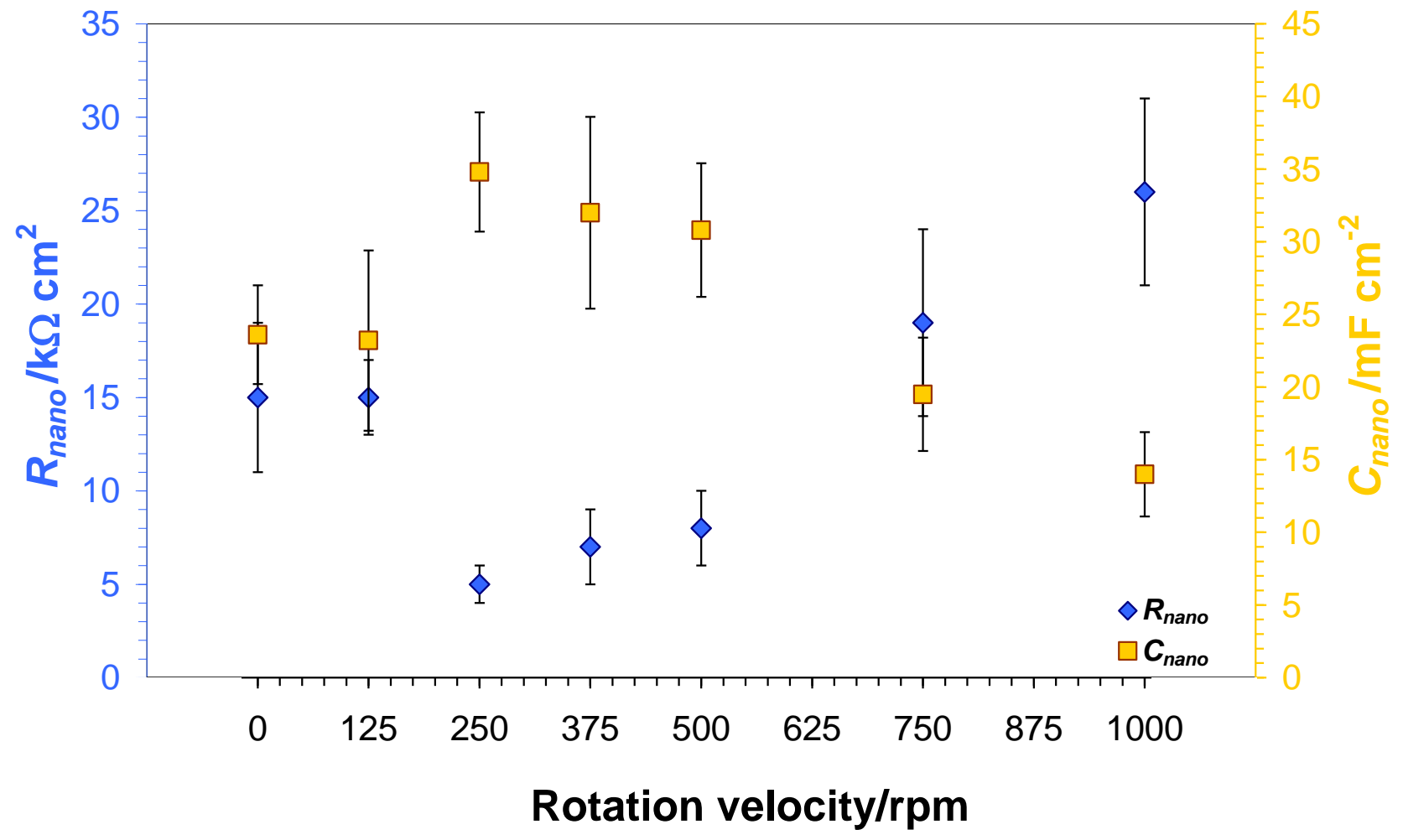


Figure 7

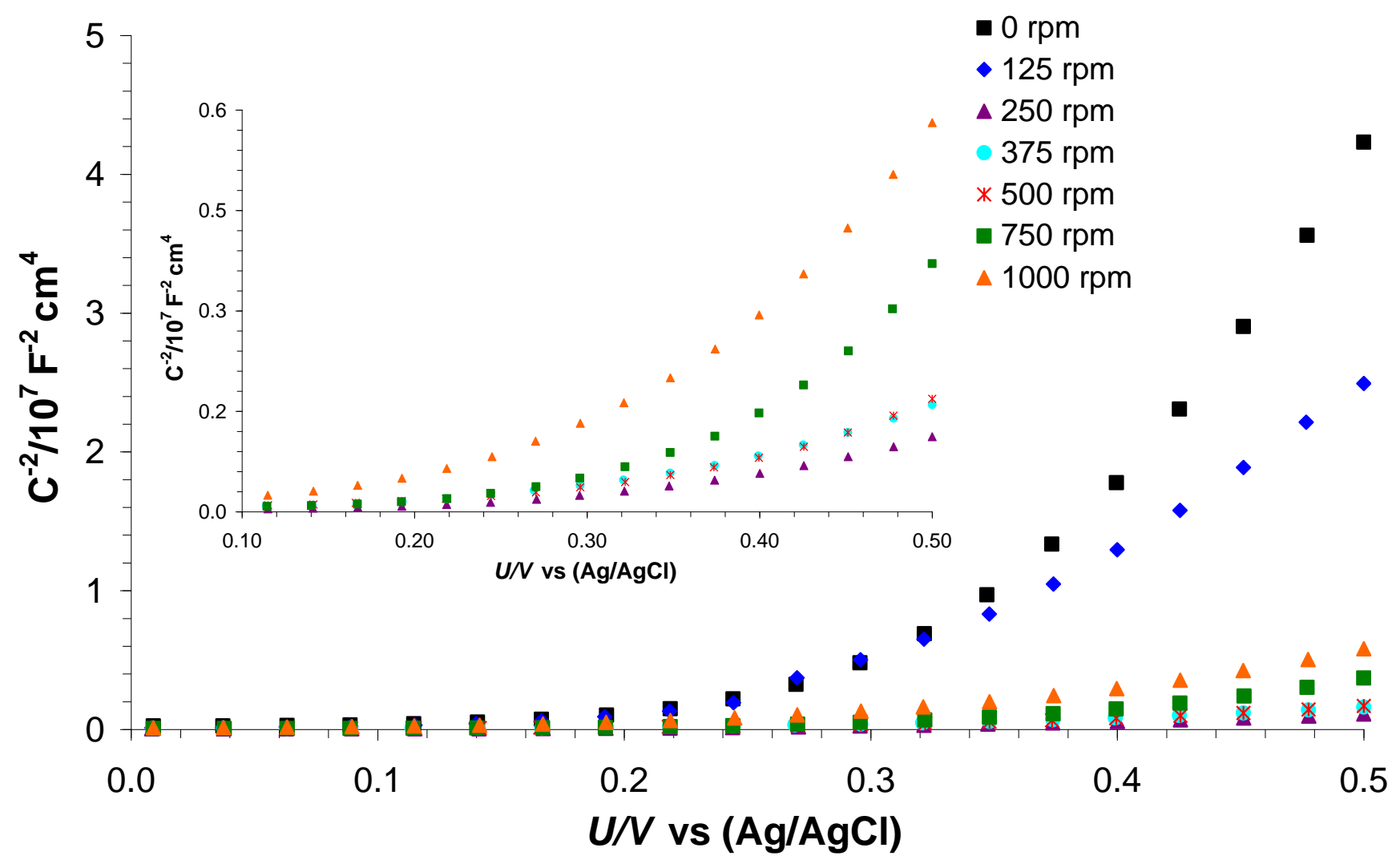



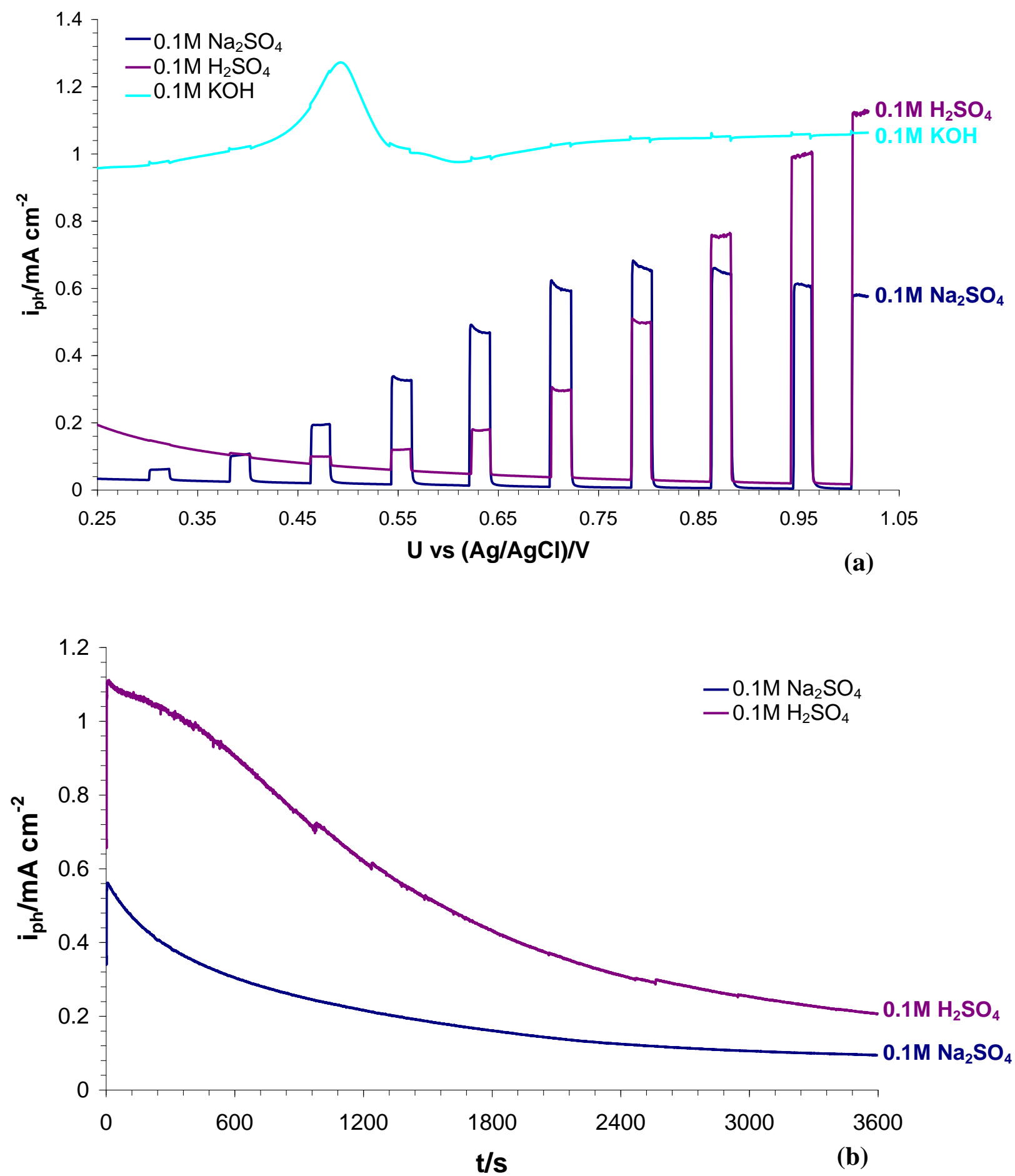

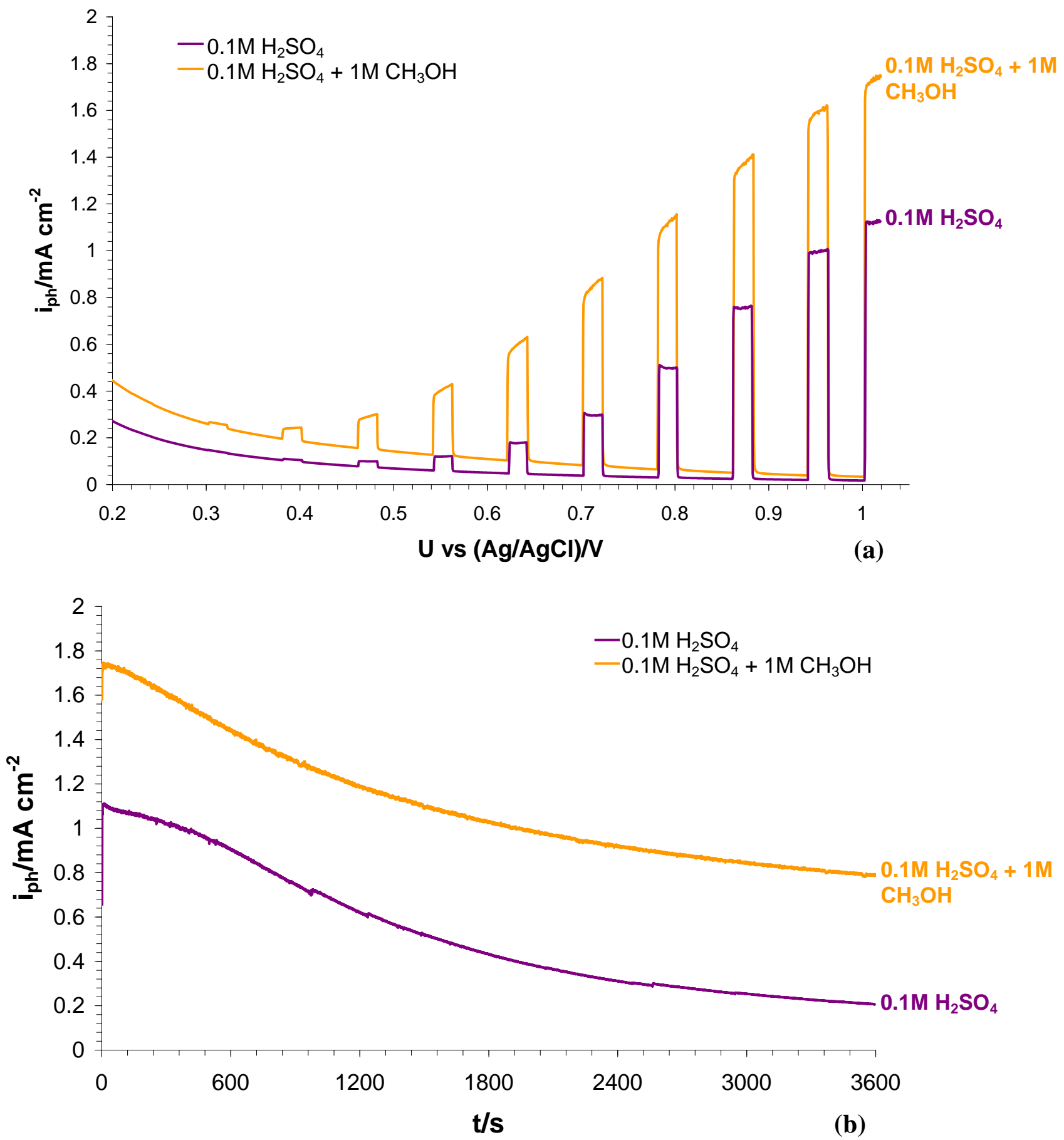

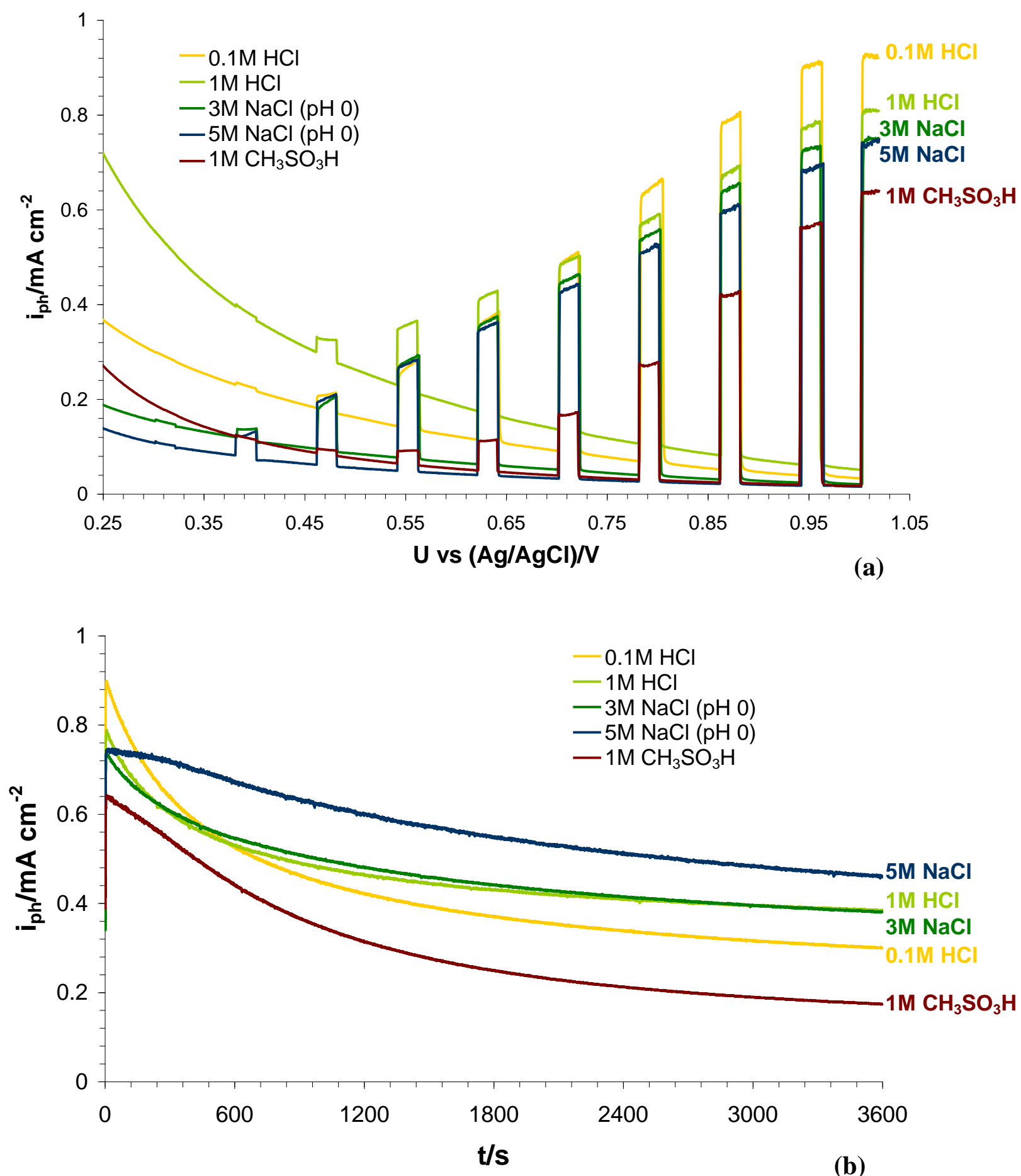

(b) 


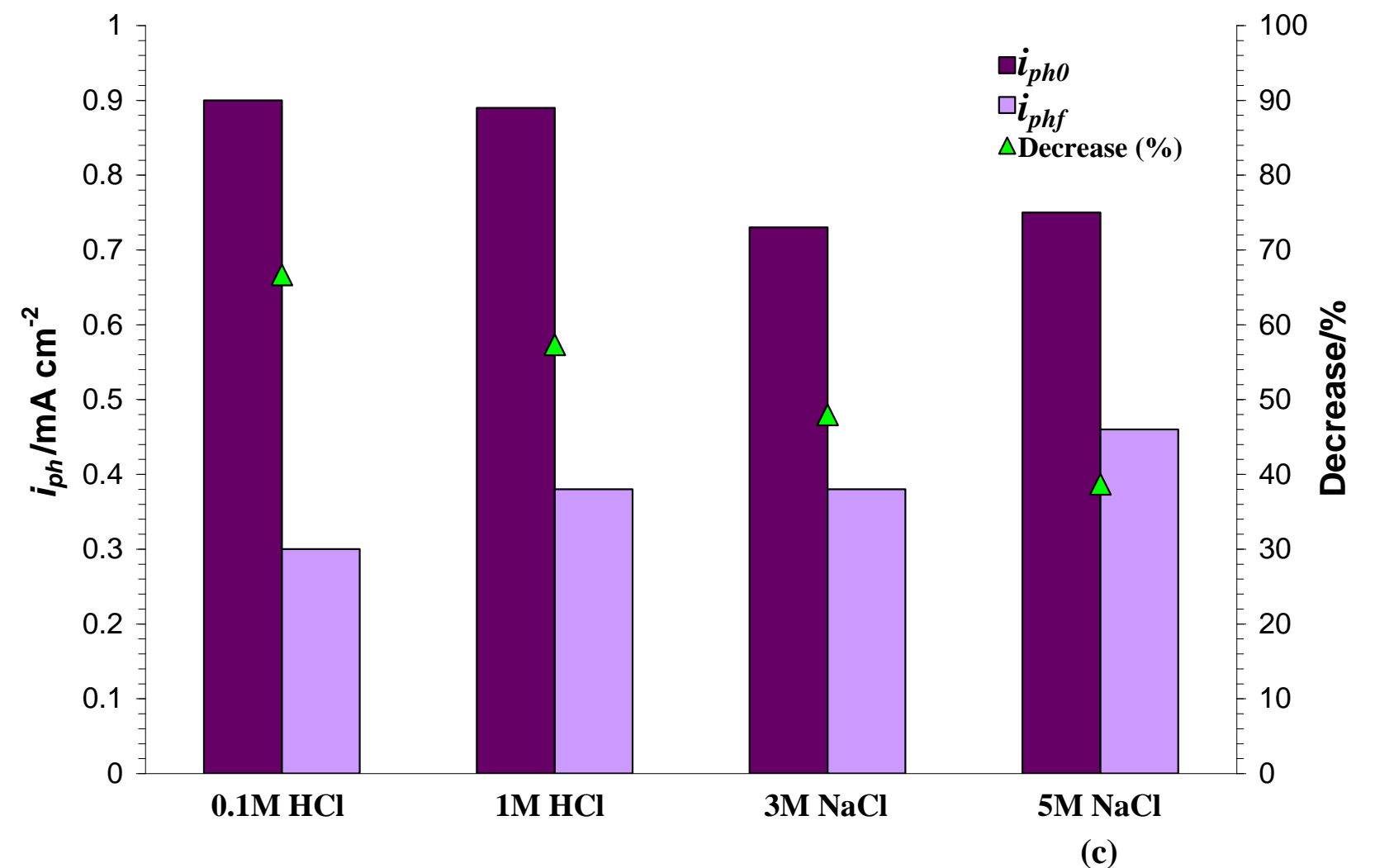


Figure 11

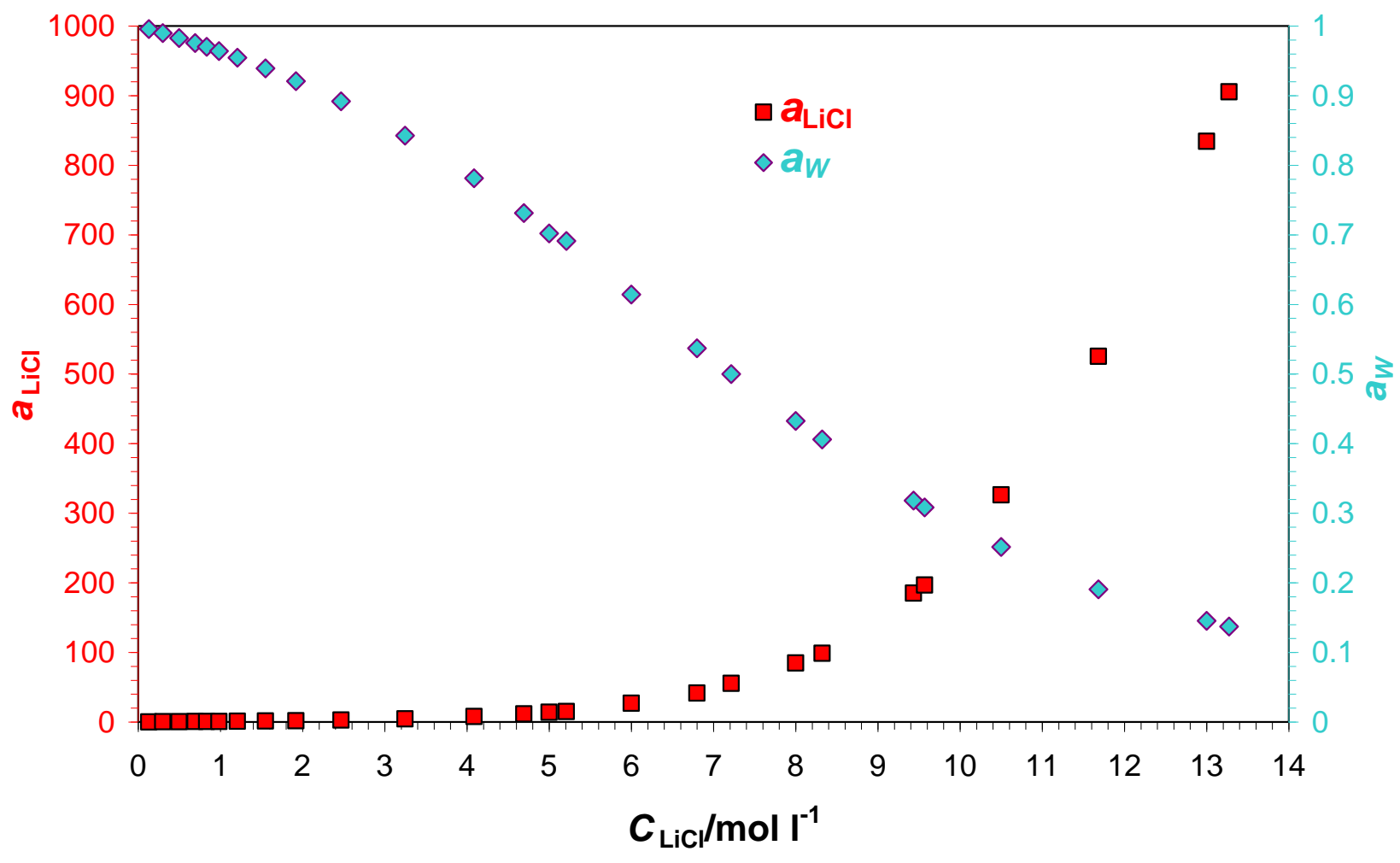



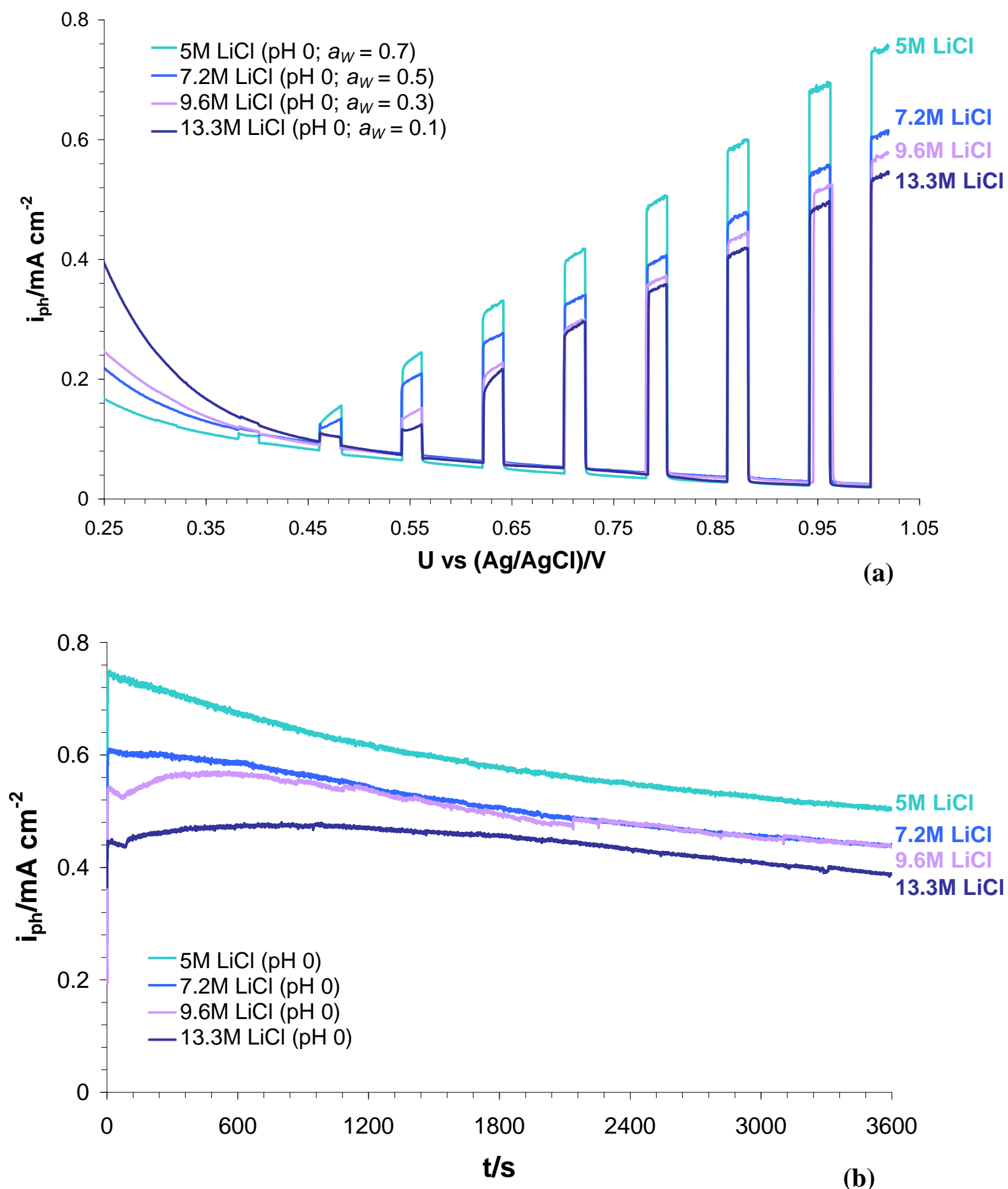

(b) 


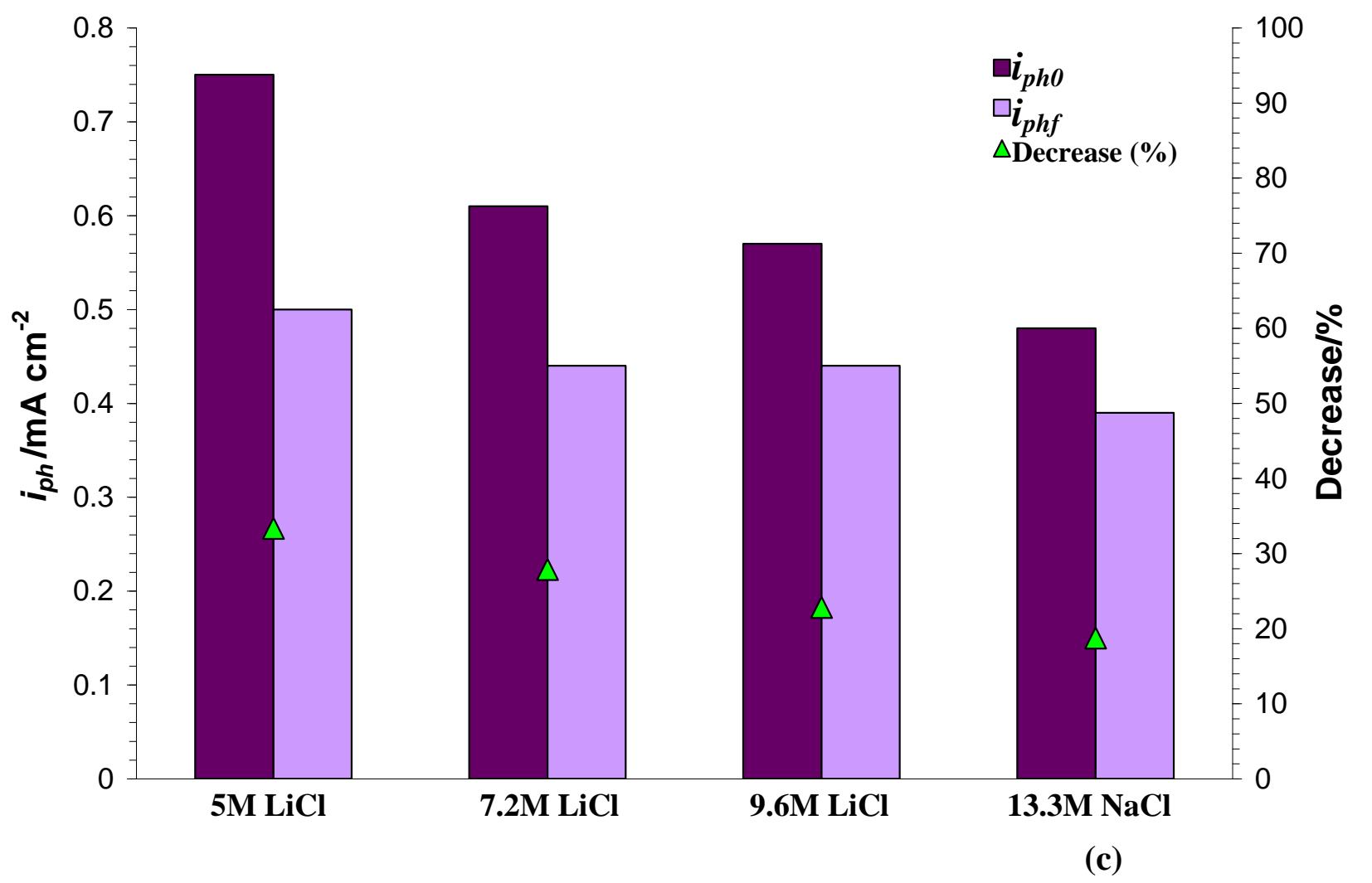



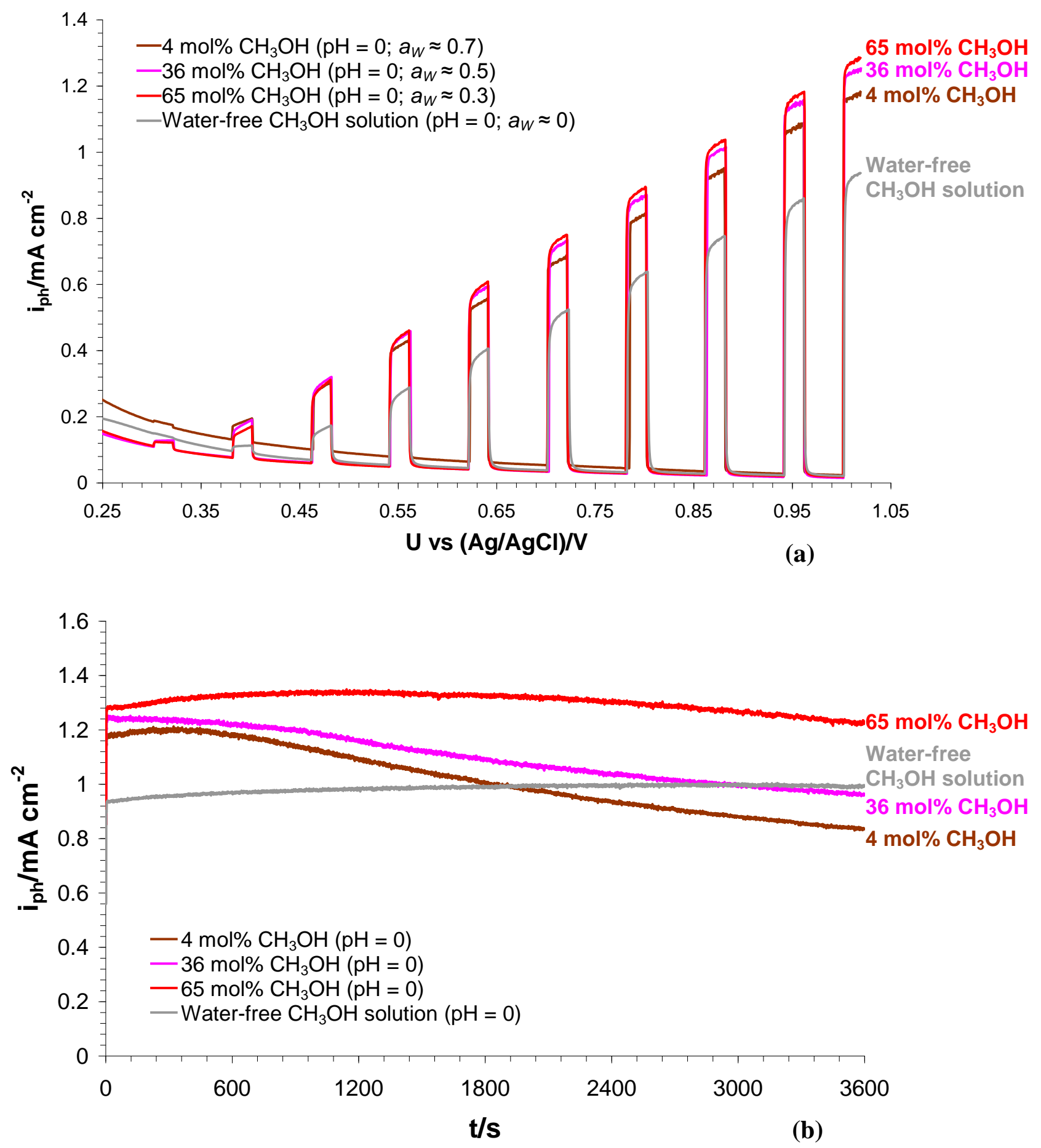


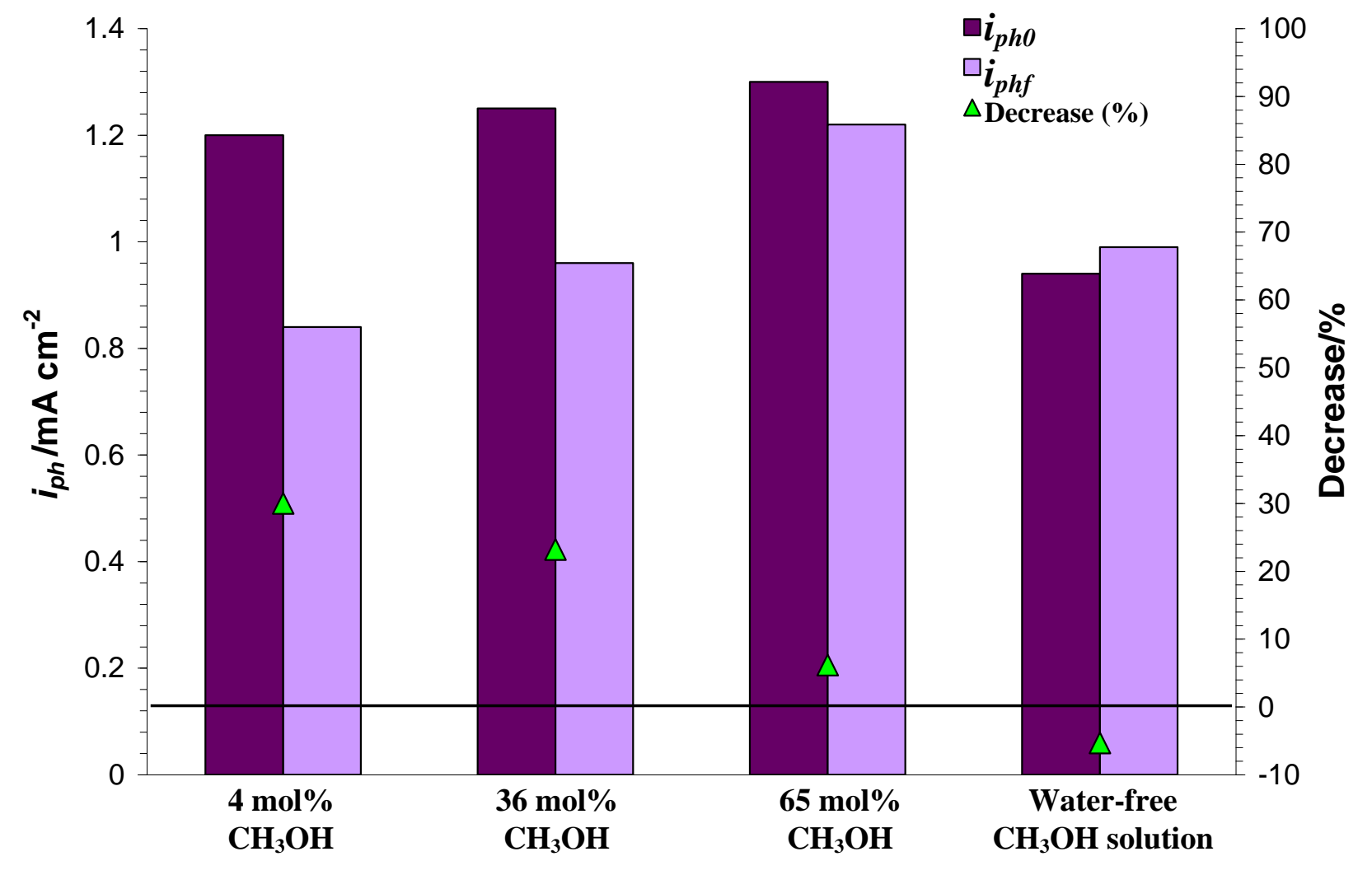

(c) 

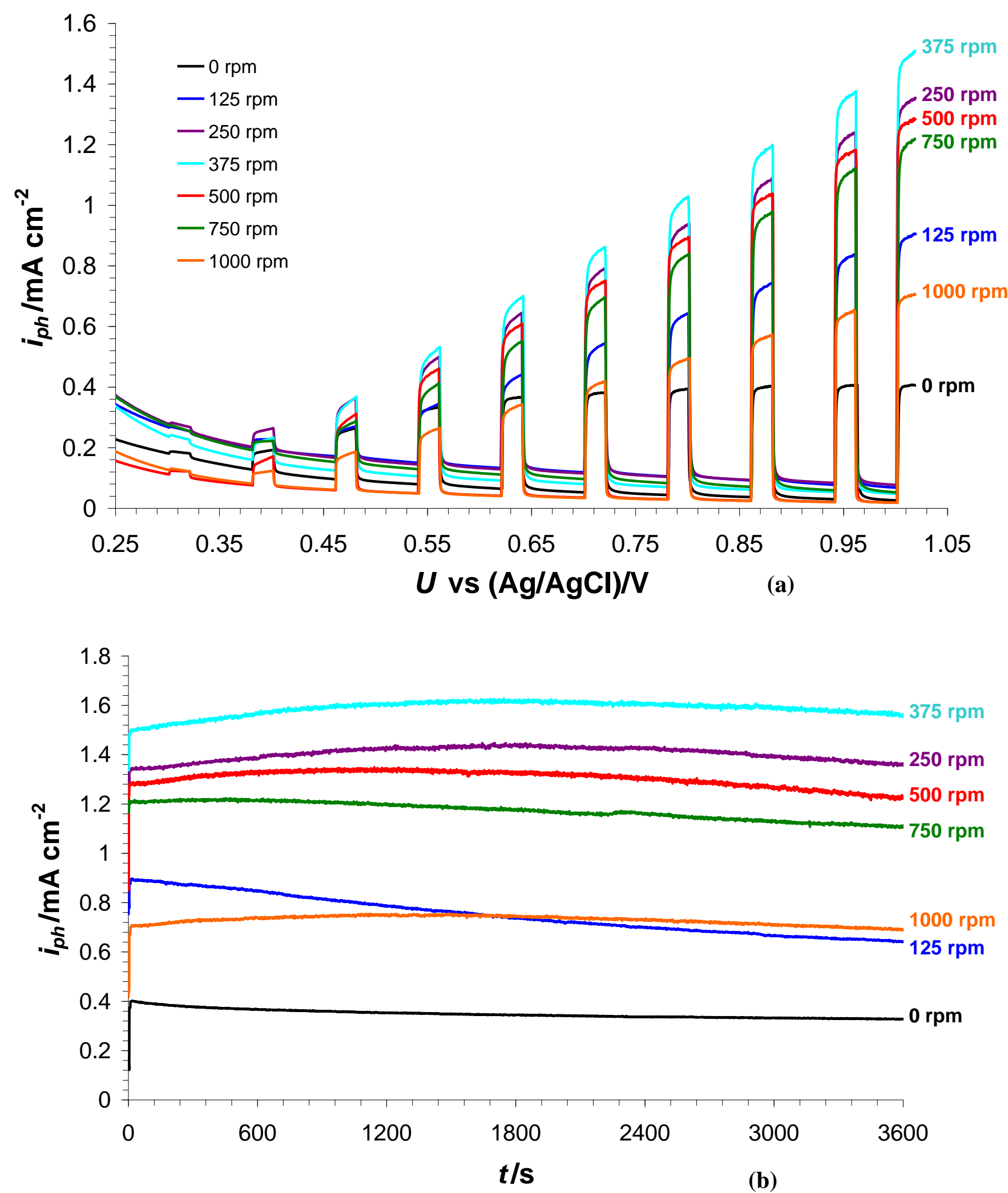


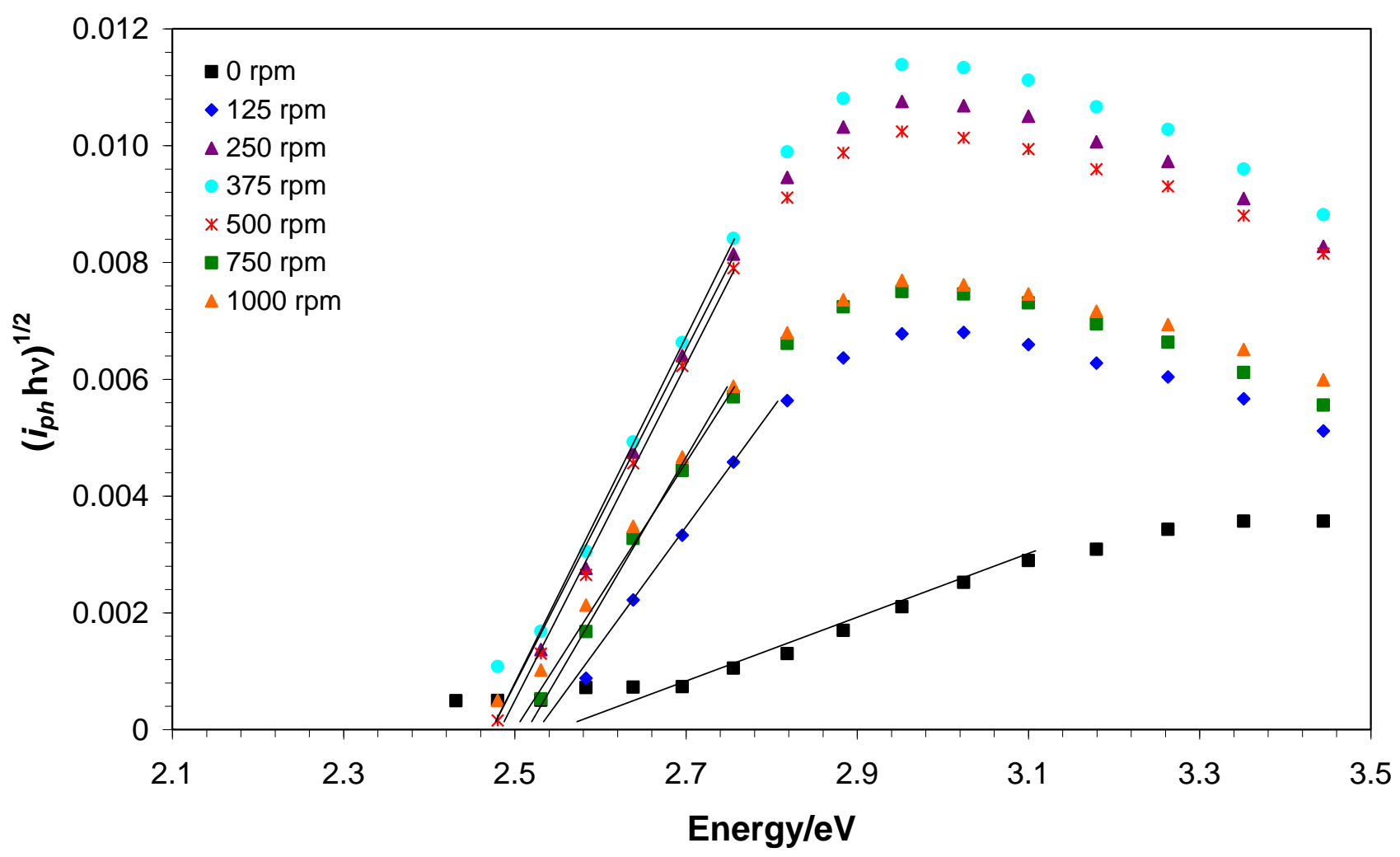




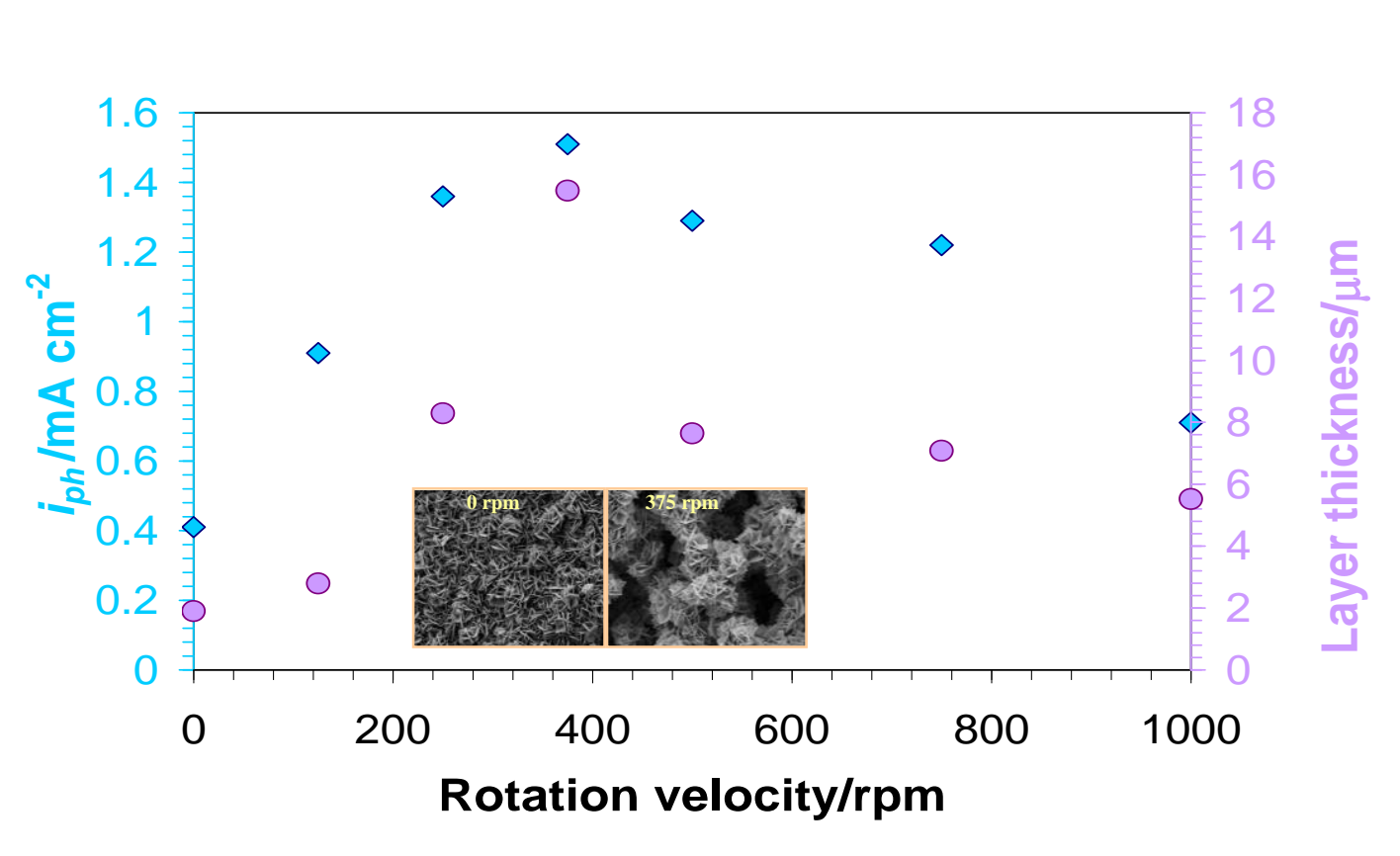

\section{Graphical Abstract}

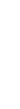

.

. 
$\mathrm{WO}_{3}$ nanoplatelet globular clusters united in a tree-like fashion were obtained

Influence of rotation velocity (RDE) during $\mathrm{W}$ anodization has been investigated

The thickest nanoplatelet layer was obtained at $375 \mathrm{rpm}$, exposing high active area

At $375 \mathrm{rpm}$, the charge-transfer resistance decreased, enhancing photocurrent response

Nanostructures were highly stable in aqueous/methanolic mixed solutions with $\mathrm{LiCl}$ 